\title{
Anisotropic Zonation in the Lithosphere of Central North America: Influence of a Strong Cratonic Lithosphere on the Mid-Continent Rift
}

\author{
O. Ola, A.W. Frederiksen ${ }^{\mathrm{a}, *}$, T. Bollmann ${ }^{\mathrm{b}}$, S. van der Lee ${ }^{\mathrm{b}}, \mathrm{F}$. \\ Darbyshire $^{\mathrm{c}}$, E. Wolin ${ }^{\mathrm{b}}$, J. Revenaugh ${ }^{\mathrm{d}}$, C. Stein ${ }^{\mathrm{e}}$, S. Stein ${ }^{\mathrm{b}}, \mathrm{M}$. \\ Wysession $^{\mathrm{f}}$ \\ ${ }^{a}$ Department of Geological Sciences, University of Manitoba, Winnipeg, Manitoba, R3T \\ 2N2, Canada \\ ${ }^{b}$ Department of Earth and Planetary Sciences, Northwestern University, 2145 Sheridan \\ Road, Evanston IL, 60208-3130, USA \\ ${ }^{c}$ Centre de recherche GEOTOP, Université du Québec à Montréal, CP 8888, succ. \\ Centre-Ville, Montréal, Québec, Canada, H3C 3P8 \\ ${ }^{d}$ Department of Earth Sciences, University of Minnesota, 310 Pillsbury Drive SE, \\ Minneapolis, MN 55455-0231, USA \\ ${ }^{e}$ Department of Earth and Environmental Sciences, University of Illinois at Chicago, 845 \\ W. Taylor St., Chicago, IL 60607-7059, USA \\ ${ }^{f}$ Department of Earth and Planetary Sciences, Washington University in St. Louis, One \\ Brookings Drive, St. Louis, MO 63130-4899, USA
}

\section{Abstract}

We present shear-wave splitting analyses of SKS and SKKS waves recorded at sixteen Superior Province Rifting Earthscope Experiment (SPREE) seismic stations on the north shore of Lake Superior, as well as fifteen selected Earthscope Transportable Array instruments south of the lake. These instruments bracket the Mid-Continent Rift (MCR) and sample the Superior, Penokean, Yavapai and Mazatzal tectonic provinces. The data set can be explained by a single layer of anisotropic fabric, which we interpret to be dominated by a lithospheric contribution. The fast $\mathrm{S}$ polarization directions are consistently ENE-WSW, but the split time varies greatly across the study Preprint submitted to Tectonophysics

May 27, 2016

${ }^{*}$ Corresponding author.

Email addresses: kunleola15@yahoo.com (O. Ola), Andrew.Frederiksen@umanitoba.ca (A.W. Frederiksen), trevor@earth.northwestern.edu (T. Bollmann), suzan@earth.northwestern.edu (S. van der Lee), darbyshire.fiona_ann@uqam.ca (F. Darbyshire), emilyw@earth.northwestern.edu (E. Wolin), justinr@umn.edu (J. Revenaugh), cstein@uic.edu (C. Stein), seth@earth.northwestern.edu (S. Stein), michael@wucore.wustl.edu (M. Wysession)

(C) 2016. This manuscript version is made available under the Elsevier user license http://www.elsevier.com/open-access/userlicense/1.0/ 
area, showing strong anisotropy (up to $1.48 \mathrm{~s}$ ) in the western Superior, moderate anisotropy in the eastern Superior, and moderate to low anisotropy in the terranes south of Lake Superior. We locate two localized zones of very low split time (less than $0.6 \mathrm{~s}$ ) adjacent to the MCR: one in the Nipigon Embayment, an MCR-related magmatic feature immediately north of Lake Superior, and the other adjacent to the eastern end of the lake, at the southern end of the Kapuskasing Structural Zone (KSZ). Both low-splitting zones are adjacent to sharp bends in the MCR axis. We interpret these two zones, along with a low-velocity linear feature imaged by a previous tomographic study beneath Minnesota and the Dakotas, as failed lithospheric branches of the MCR. Given that all three of these branches failed to propagate into the Superior Province lithosphere, we propose that the sharp bend of the MCR through Lake Superior is a consequence of the high mechanical strength of the Superior lithosphere ca. 1.1 Ga.

Keywords: Mid-Continent Rift, Superior Province, shear-wave splitting, lithosphere, anisotropy, Nipigon Embayment.

\section{Introduction}

Rifting a continent necessarily involves both the crust and the entire lithosphere. The mechanical strength of the continental lithosphere plays an important role in this process (Gueydan et al., 2008; Huismans and Beaumont, 2011), as the presence or absence of a strong lithosphere is a major control on the geometry and deformation mechanisms of the evolving rift. In addition, the mechanical fabric of the lithosphere may influence the directionality of the rifting process (Tommasi and Vauchez, 2000). Rifting processes are, 
to some extent, recorded in the lithospheric fabric beneath active (Bastow et al., 2010) as well as long-stable (Vauchez et al., 2000) rift zones, though strain localization in active rifts implies that broad anisotropic features will primarily record the early stages of rift development.

The Mesoproterozoic Mid-Continent Rift (MCR), in central North America, abuts on the Archean Superior Province (SP), the largest Archean craton in existence. The MCR cross-cuts the Proterozoic Penokean, Yavapai and Mazatzal orogens with both its eastern and western arms (Fig. 1), but avoids penetrating deep into the SP, instead bending sharply through Lake Superior. The MCR was recently instrumented with broadband seismographs as part of the Superior Province Rifting Earthscope Experiment (SPREE; Stein et al., 2011; Wolin et al., 2015), yielding the first detailed seismic constraints on the lithosphere of the MCR/Superior contact. In this study, we present the first observations of upper-mantle anisotropy made using this data set. We measure the S polarization anisotropy of the upper mantle using SKS splitting methods, control for possible non-lithospheric sources of splitting effects, interpret the measured splitting in terms of variations in lithospheric fabric, and examine the relationship between the MCR and the SP lithosphere. We suggest that rifting did not extend further to the north owing to the strong SP lithosphere, though MCR magmatism may have propagated into the Superior lithosphere in several places.

\section{Tectonic and geophysical background}

The Canadian Shield, the Precambrian core of North America, is an amalgam of Archean and Proterozoic tectonic blocks and orogens. The largest of 
the Archean blocks is the Superior Province, which stabilized ca. 2.6 Ga via accretion of a series of older terranes (Card, 1990; Calvert and Ludden, 1999; Percival et al., 2006). In the western Superior, these terranes form narrow belts with a consistent E-W alignment; sutures between these belts have been found to traverse the Moho in Lithoprobe seismic sections (White et al., 2003), indicating that tectonic accretion had a role in the formation of the Superior lithosphere. The lithosphere beneath the Superior Province is thick and seismically fast (Darbyshire et al., 2007; Frederiksen et al., 2007, 2013a) as well as strongly anisotropic (Darbyshire and Lebedev, 2009; Frederiksen et al., 2013b; Ferré et al., 2014), possibly as a result of accretionary processes. The lithosphere beneath the eastern Superior is seismically slower and contains an anomaly attributed to the Great Meteor hotspot track (Rondenay et al., 2000; Eaton and Frederiksen, 2007; Frederiksen et al., 2007). The eastern Superior was affected by uplift along the ca. 1.9 Ga Kapuskasing Structural Zone (KSZ; Percival and West, 1994).

The Superior Province is surrounded by Proterozoic orogens (Fig. 1). The oldest of these are the roughly contemporaneous Trans-Hudson and Penokean orogens, which accreted to the west and south of the Superior, respectively, ca. 1.8 Ga (Whitmeyer and Karlstrom, 2007). The Yavapai and Mazatzal orogens accreted further juvenile crust ca. 1.7 and $1.6 \mathrm{Ga}$, respectively, followed by extensive plutonism (Whitmeyer and Karlstrom, 2007; Amato et al., 2008). Further accretion continued southward with the Granite-Rhyolite Province ca. 1.55-1.35 Ga, which extends beyond our study area (Whitmeyer and Karlstrom, 2007). The last and largest of these orogens is the Grenville Orogen, which accreted to the east of the Superior in stages from 1.3 to 1.0 
Ga as part of a major continent-continent collision (Davidson, 1998).

While Grenvillian orogenesis was in progress, a major magmatic feature cross-cut the preexisting Penokean, Yavapai and Mazatzal provinces: the Mid-Continent Rift (MCR). The MCR is a ca. $3000 \mathrm{~km}$ long, arcuate rift structure that curves through Lake Superior, with arms extending southwest and southeast (Van Schmus and Hinze, 1985; Ojakangas et al., 2001); rifting along the MCR may have been related to the opening of an ocean between Amazonia and Laurentia ca. 1.1 Ga (Stein et al., 2014). The rift contains large volumes of basaltic magma, generating a significant gravity anomaly (see, e.g., Merino et al., 2013); the high volume and geochemistry of the basalts suggest hotspot participation in the rifting process (Hutchinson et al., 1990; White, 1997; Hollings et al., 2012, 2014) and the MCR has been described as a hybrid of a rift and a large igneous province (Stein et al., 2015). A late compressional stage of the MCR's development may have reactivated structures related to the KSZ (Manson and Halls, 1997).

The Nipigon Embayment (NE; Fig. 1) is a magmatic feature north of Lake Superior, adjacent to the most sharply-curved section of the MCR. Its mafic and ultramafic rocks are contemporaneous with the early stages of the MCR (Hollings et al., 2007), but are predominantly emplaced in the form of sills rather than dykes. The dominance of sills is suggestive of a non-extensional tectonic regime (Hart and MacDonald, 2007), though sills are not in themselves incompatible with extensional processes. The NE has been found to overlie anomalous mantle in a number of studies (Ferguson et al., 2005; Frederiksen et al., 2007, 2013a).

Limited geophysical constraints are available on the lithosphere of the 
MCR. The MCR crust was examined by the Great Lakes International Multidisciplinary Program on Crustal Evolution (GLIMPCE), which included a number of marine seismic reflection surveys performed within Lake Superior (Cannon et al., 1989). These surveys revealed varying asymmetry along the rift, and evidence for significant crustal thinning during rifting, followed by a late-stage compressional event (Mariano and Hinze, 1994; Samson and West, 1994; Sexton and Henson, 1994). The western arm of the MCR was examined using ambient noise and surface-wave tomography by Shen et al. (2013), who found thickened crust along the MCR and an intermittent low-velocity feature in the lithospheric mantle beneath the rift axis. The teleseismic Pwave model of Frederiksen et al. (2013a) also showed a low-velocity anomaly at lithospheric depth (50-250 km) beneath part of the western arm, but its resolution of the MCR is limited. The lithospheric expression of the MCR at regional scales has not been well imaged by published studies, nor has the relationship between the MCR and the lithospheric anomaly beneath the NE.

\section{Data and processing}

Deployment of the Earthscope Transportable Array (TA) reached Minnesota in 2010 and Wisconsin in 2011, occupying the south shore of Lake Superior from mid-2011 through mid-2013 with instruments spaced approximately $70 \mathrm{~km}$ apart. To coincide with this deployment, 83 broadband Earthscope FlexArray instruments were deployed in the Superior Province Rifting Earthscope Experiment (SPREE; Stein et al., 2011; Wolin et al., 2015). The SPREE deployment consisted of dense lines of instruments along and across 
the axis of the southwest arm of the MCR, in Minnesota and Wisconsin, along with a sparser deployment of stations north of Lake Superior, in Ontario, at a spacing comparable to the TA (Fig. 2). In this study, we examine data from the sixteen Canadian SPREE stations as well as fifteen selected TA stations south of Lake Superior, thus building a data set that straddles the meeting point of the eastern and western arms of the MCR. Eight of the TA stations (C39A, C40A, D37A, D41A, E38A, E39A, E43A, and E44A) were previously analyzed in Frederiksen et al. (2013b) using the same approach as is used here; the results in this study are based on a larger data set and should be considered more robust.

In an anisotropic layer, an incoming $\mathrm{S}$ wave will excite one or both of two possible shear-like (quasi-S) wave modes with different velocities; if the anisotropy is weak, the two quasi-S modes will have approximately orthogonal polarizations. We use teleseismic ray paths (SKS and SKKS) that have a radial plane polarization in the absence of anisotropy, and are near-vertical in the upper mantle; thus, we are able to observe the effect of anisotropy on a vertically-propagating wave of varying polarization, as SKS waves from earthquakes in different regions will arrive along different azimuths and so with different directions of polarization. Analysis of the SKS or SKKS pulse yields the polarization azimuth of the faster (qS1) mode, often referred to in the literature as the "fast direction" or "fast axis" (though we use the term "fast polarization direction" in this paper), as well as the time separation between the two quasi-S modes, which is known as the "split time". If the incident SKS wave travels near-vertically, the fast S polarization direction obtained by splitting analysis may be attributed to the projection of 
material fabric onto the horizontal plane, while the split time represents a combination of the thickness and strength of this projected fabric.

We obtained data for events of magnitude $\geq 6$ at distances corresponding to angles from $90^{\circ}$ to $130^{\circ}$ from a point at the centre of the array $\left(47.79^{\circ} \mathrm{N}, 87.70^{\circ} \mathrm{W}\right)$. In this distance range, the SKS pulse is expected to be well-separated from other body-wave arrivals, and so is suitable for splitting analysis. Of the 196 events considered, 128 events exhibited usable (i.e., of quality $\geq 3$; see below for details) SKS or SKKS pulses at at least one station. For each trace, the data were filtered in a frequency band of 0.02$0.2 \mathrm{~Hz}$, windows were manually chosen around the expected SKS and SKKS arrival times, and a Hanning taper was applied to the ends of the SKS and SKKS windows.

The earthquakes for which usable SKS or SKKS pulses were obtained (Fig. 3a) are concentrated in back azimuths ranging from WSW clockwise to NNE, with a few scattered events from the south. This gives nearly continuous coverage over almost half of the possible back-azimuth range. If we assume that the incident SKS and SKKS waves travel nearly vertically in the upper mantle, then their splitting should depend only on the polarization plane of the incident wave, which will be the same for two events $180^{\circ}$ apart in back azimuth. If we consider only the polarization directions (back azimuths modulo $180^{\circ}$ ) of these events, we have nearly complete coverage (Fig. 3b), with all but one $10^{\circ}$ swath containing at least one event. In the case of layered anisotropy with horizontal fast axes, the anisotropic response will have $180^{\circ}$ back-azimuthal symmetry and will depend only on the polarization direction, even for a non-vertical incidence angle; if a plunging anisotropic symmetry 
axis or a dipping interface are present, the symmetry will be broken. Given that our data are largely restricted to a single hemisphere, and that we are considering SKS and SKKS arrivals with very steep incidence angles, we will be unable to detect deviations from layered structure and horizontal axis orientations. However, our very complete polarization-direction coverage will allow us to detect the effect of multiple anisotropic layers, should they be present.

A crude estimate of the anisotropic influence on these data may be obtained by examining the average ratio of transverse to radial energy in the SKS or SKKS pulse. In an isotropically layered Earth, the transverse component of a core-refracted wave should consist entirely of noise. If anisotropic material is present on the receiver side of the ray path, there will be coherent energy on the transverse component, unless the earthquake is aligned with one of the anisotropic symmetry axes; if we average the ratio of transverse to radial energy over a range of event azimuths, we expect that stations with stronger anisotropy will exhibit a higher ratio of transverse energy. We averaged the transverse/radial (T/R) energy ratio for all acceptable SKS and SKKS time windows at each station (Fig. 4). The map is spatially coherent over long distances, indicating that the $T / R$ ratio is measuring large-scale structure rather than localized effects at individual sites. The high ratios north of Lake Superior indicate that SKS waves deviate strongly from radial polarization at these stations, indicating a strong anisotropic influence.

Shear-wave splitting analysis for individual events was carried out using the eigenvalue minimization approach of Silver and Chan (1991), in which a grid search is performed over a range of split time $(\delta t)$ and fast $\mathrm{S}$ polarization 
azimuth $(\phi)$ values to find the values that, when applied as a correction, minimize the second eigenvalue of the covariance matrix between the corrected traces, and so recover the most linear initial particle motion (Fig. 5). As an additional check, we also minimized the energy on the corrected transverse component, which should yield approximately the same result. Based on plots similar to Fig. 5, we assigned a quality to each SKS and SKKS pulse on a subjective scale from 0 through 5 , based on the apparent noise level on the input traces, the degree of linearization of the particle motion, the degree of minimization of the transverse energy, and the correspondence between the eigenvalue and transverse-energy solutions. Only traces with quality levels of 3 or more were retained for further analysis; examples of arrivals with qualities of 3,4 and 5 are provided as supplementary figures.

The single-event measurements at each station show considerable scatter (Fig. 6), particularly in the recovered split time. This is a problem inherent to shear-wave splitting analysis: single events are more sensitive to fast $\mathrm{S}$ polarization direction than split time, and often a considerable portion of the $\phi, \delta t$ surface returns low values of misfit (Fig. 5). Particularly strong ambiguities arise when the incident-wave polarization is close to the polarization of the fast or slow quasi-S wave, in which case no splitting is observed, the split time is not constrained, and there is a $90^{\circ}$ ambiguity in fast $\mathrm{S}$ polarization direction. As noted by Wolfe and Silver (1998), the error surface (i.e., the value of the second eigenvalue of the covariance matrix, calculated over a grid of $\phi, \delta t$ values) is a more robust observable than the actual splitting parameters, so averaging error surfaces over multiple events is a safer approach than averaging together single-event splitting measurements if a 
single-layered model is sufficient to explain the data.

The single-event measurements from our data set (Fig. 6) are too scattered to indicate whether the splitting parameters vary systematically with back azimuth, which would be an indicator of complex or multilayered anisotropic structure. To check for back-azimuthal variations, we stacked the error surfaces for events falling in polarization swaths at each station (Fig. 7), with the polarization direction taken as the back azimuth modulo $180^{\circ}$ (i.e., the remainder of the back azimuth $\div 180^{\circ}$ ). The swaths used are the same as the ones used in the histogram in Fig. 3b. The swath-stacked error surfaces for the example station vary significantly by direction, with some directions (e.g., $140^{\circ}-150^{\circ}$ ) showing a null-like pattern with $90^{\circ}$ directional ambiguity and no split-time resolution, and others (e.g., $90^{\circ}-100^{\circ}$ ) constraining the split time while having limited directional resolution. The final set of splitting parameters (white dots on all panels) fall in low-misfit regions in all of the swaths, indicating that a one-layer model is compatible with the entire data set, though the differences between some swaths (e.g., $90^{\circ}-100^{\circ}$ and $130^{\circ}-140^{\circ}$ ) suggest that more complex structures may be present. The sample station is typical of the data set, in that none of the stations examined unambiguously required multiple anisotropic layers to explain the observed error surfaces. Therefore, we proceeded with a one-layer analysis at all stations.

Final measurement of splitting parameters was done using a directionallybalanced variant (Frederiksen et al., 2006, 2007, 2013b) of the error-surface stacking method of Wolfe and Silver (1998). The error surfaces were stacked twice, first by forming directional swaths as described above, and then by stacking the swath stacks with equal weight. This last procedure evens out 
the directional coverage (within the limitations of the data set) and so yields results that are not dominated by the most seismically-active directions. The minimum quality threshold for inclusion in the stack was taken to be either 3 or 4 depending on the number of available events at the station and the appearance of the stacked error surface. The final stack of all swaths (Fig. 8) yielded an estimate of the splitting parameters at the station, as well as an error bar (Figure 9b) obtained from the error surface using the Fischer F-test (Silver and Chan, 1991); the obtained error bar treats the composite error surface as though it were obtained from a single trace, and is therefore a pessimistic estimate. At station $\mathrm{D} 46 \mathrm{~A}$, the measured split time of $0.28 \mathrm{~s}$ is less than the error bar of $\pm 0.33 \mathrm{~s}$, indicating a null measurement (anisotropy is not necessary to explain the data). Stations SC07 and K42A are near-null cases where the error bar comes within $0.05 \mathrm{~s}$ of the split time, so their fast S polarization directions should be interpreted with caution.

\section{Results}

The final splitting parameters are given in Table 1 and plotted as directional arrows in Fig. 9a. The map also includes results from a number of other studies in the area, divided into measurements done using the same methodology as our study (Frederiksen et al., 2006, 2007, 2013b) and other published measurements (Silver and Kaneshima, 1993; Barruol et al., 1997; Kay et al., 1999; Rondenay et al., 2000; Eaton et al., 2004; Ferré et al., 2014). The study of Yang et al. (2014) is omitted from this map due to a difference in methodology - unlike the other splitting measurements shown here,their measurements are based on averaging of single-event splitting measurements 
rather than the stacking of error surfaces. As noted by Kong et al. (2015), splitting results obtained by averaging splitting parameters rather than stacking error surfaces tend to produce somewhat higher averaged split times from the same data sets; we have therefore excluded the Yang et al. (2014) measurements from our quantitative analysis, though their spatial pattern is in keeping with the other studies.

Of the 31 stations we examined, all but one of the fast polarization directions lie within the northeast quadrant, ranging from $36^{\circ}$ to $107^{\circ}$ (the one exception) with an average of $69^{\circ}$ and a standard deviation of $14^{\circ}$. The exception is D46A, which, as noted above, is a null measurement whose fast polarization direction may not be meaningful. A contour plot of the fast $\mathrm{S}$ polarization directions is shown in Fig. 10. North of Lake Superior, the fast polarization azimuth is consistently close to $70^{\circ}$ (ENE-WSW); immediately south of the lake, there is more variability, with some stations having fast polarization directions closer to $45^{\circ}$ (NE-SW), while ENE-WSW directions resume further south. Looking at variations over a broader area (including previous studies), we can see that the fast polarization direction rotates to NE-SW between 44 and $49^{\circ} \mathrm{N}$ along the western edge of the map area, and to $\mathrm{E}-\mathrm{W}$ in the SE corner of the map.

The split time (Fig. 11) shows considerable variation over the study area, averaging $0.62 \mathrm{~s}$ with a standard deviation of $0.26 \mathrm{~s}$. SPREE stations north of Lake Superior and west of ca. $89^{\circ} \mathrm{W}$ exhibit split times of $0.8 \mathrm{~s}$ or greater, including our strongest observed split (1.48 s at SC02). East of $89^{\circ} \mathrm{W}$, stations north of the lake exhibit moderate to low split times, with split times less than $0.6 \mathrm{~s}$ concentrated in two clusters along the lakeshore: 
one centered at $49^{\circ} \mathrm{N}, 88^{\circ} \mathrm{W}$, at the western edge of the Nipigon Embayment, and one at $47^{\circ} \mathrm{N}, 84^{\circ} \mathrm{W}$ at the eastern end of Lake Superior. South of the lake, split times are also low, and decrease southward into the Mazatzal Orogen.

\section{Discussion}

\subsection{Depth of anisotropic variations}

Shear-wave splitting of teleseismic phases is diagnostic of anisotropic fabric, but provides no direct constraint on the depth of the anisotropy. When core-refracted phases are used, as is done here, the splitting effect is physically limited to the receiver-side path above the core-mantle boundary, but in principle, the anisotropy calculated from a split SKS or SKKS pulse may be present at any depth between the receiver and the core-mantle boundary (CMB).

Whole-mantle tomographic models that include anisotropy (e.g., Panning and Romanowicz, 2006; Auer et al., 2014) typically assume radial anisotropy (i.e. anisotropy with a vertical symmetry axis), in contrast to the azimuthal anisotropy (anisotropy with a horizontal symmetry axis) that shear-wave splitting is able to detect. These models generally show that the strongest anisotropy present is in the upper mantle, but that anisotropy in $\mathrm{D}^{\prime \prime}$ is also strong. Targeted body-wave studies (e.g.. Garnero et al., 2004; Long, 2009; He and Long, 2011; Nowacki et al., 2010) detected significant azimuthal anisotropy in portions of $\mathrm{D}^{\prime \prime}$, the strongest fabric being associated with regions of inferred downwelling (Pacific subduction zones) and upwelling (large low-shear-velocity provinces; Garnero and McNamara, 2008). As SKS ray paths necessarily pass through the $\mathrm{D}^{\prime \prime}$ layer, it is likely that our data set 
contains some degree of contamination from the base of the mantle, and possible that the cumulative effect of weak mid-mantle anisotropy may also affect our data. Our use of eigenvalue minimization for splitting analysis, which maximizes the linearity of the incident wave's polarization, is robust in the presence of deviations from SV polarization, and in any case we have not observed any systematic deviations of this nature. Therefore, it is only deep-mantle anisotropy capable of splitting the SKS wave that must be considered.

To address this, we examined splitting parameters for individual events averaged over all stations for which the event was recorded with acceptable quality. This is a somewhat ad hoc approach that cannot completely isolate deep-mantle effects. However, the averaging should enhance the effect of deep-Earth contributions, as the ray paths for an event will be closer together at the CMB than in the lithosphere. The resulting maps (Fig. 12) show coherent spatial variations in the fast S polarization direction (upper panel), with nearby events generally exhibiting similar fast polarizations. The split time (lower panel), which is more difficult to measure robustly from single events, shows no obvious coherence. We take the coherent fast-polarization clusters to be evidence of at least some deep-mantle influence on our data set.

The relatively short spatial wavelength of variations in the event-averaged fast S polarization direction (Fig. 12, upper) suggests that the deep-mantle contribution to our split measurements is not systematic over large distances, and so may be suppressed by directional averaging. The general consistency observed in swath-stacked misfit surfaces (see e.g., Fig. 7) suggests that 
deep-mantle contributions are already being averaged away within individual polarization swaths. Furthermore, our two-stage stacking approach, in which the swath stacks are themselves stacked with equal weight to form composite error surfaces for each station, should suppress any remaining directional variation. We will therefore interpret our station-averaged results under the assumption that they represent only upper-mantle anisotropy. We further adopt the commonly-made assumption that upper-mantle anisotropy is dominantly due to the preferential alignment of olivine crystals (see e.g. Nicolas and Christensen, 1987; Silver, 1996), and so that our measurements reflect fabric above the $410 \mathrm{~km}$ discontinuity, below which the olivine phase is absent.

The remaining possible depth ranges for the anisotropy we observe are the asthenosphere (representing active deformation), the lithosphere (representing frozen deformation), and the crust. The crustal contribution to shearwave splitting may be evaluated based on existing constraints on crustal structure. In particular, the velocity structure of the western Superior Province north of Lake Superior was examined using two perpendicular refraction lines (Musacchio et al., 2004) as a component of the Lithoprobe Western Superior transect. The refraction survey located a $\approx 10 \mathrm{~km}$-thick lower crustal layer with $\mathrm{P}$ velocities of $7.5 \mathrm{~km} / \mathrm{s}$ and $6.9 \mathrm{~km} / \mathrm{s}$ in perpendicular directions, representing $8.3 \% \mathrm{P}$ anisotropy if the fast quasi-P axis is parallel to the northsouth line (i.e., perpendicular to the locally E-W geologic strike of Superior subprovinces); assuming the $\mathrm{S}$ velocity has the same symmetry axis (which will be the case for simple anisotropic symmetry models) and a comparable percentage of anisotropy, this layer would generate a split of $\approx 0.2 \mathrm{~s}$ between 
the fast and the slow wave. Even if strongly anisotropic, thick layers like this were a common feature in the Superior crust, their contributions would be insufficient to account for more than a small part of the observed splitting. Ferré et al. (2014) also concluded that the crustal contribution to SKS splitting is weak in the southwest Superior, based on modelling of the seismic effects of observed metamorphic foliation.

The question of asthenospheric versus lithospheric contributions is more difficult to answer. The vast majority of the fast polarization directions we observe are parallel to the direction of absolute plate motion calculated from model HS3-NUVEL-1A (Fig. 9, green arrow; Gripp and Gordon, 1990) as well as to the general tectonic fabric of the western Superior Province; the absolute plate motion direction in this area is consistent between different plate-motion models, and is fairly uniform over the study area. The split times, by contrast, vary significantly over short length scales (Fig. 11). For a ray of approximately $11,000 \mathrm{~km}$ in length (typical for a teleseismic SKS phase) recorded at $0.2 \mathrm{~Hz}$, the Fresnel zone at $250 \mathrm{~km}$ depth will be $\approx 106$ $\mathrm{km}$ in diameter, indicating that stations less than this distance apart will be sampling overlapping volumes within the asthenosphere. Given that the split times we observe vary rapidly over short distances (SC04 and SC07 are $120 \mathrm{~km}$ apart and have split times of 0.90 and 0.25 , respectively; SC05 and C40A are $46 \mathrm{~km}$ apart and have split times of 0.85 and 0.55 ), we conclude that, though there may be some asthenospheric contribution to the regional anisotropy, the spatial variations that we see are the result of variations within the lithosphere. It is worth bearing in mind, however, that strong topography on the lithosphere-asthenosphere boundary can modify the as- 
thenospheric flow pattern and cause local flow to be enhanced by channeling effects, a process which can enhance shear-wave splitting (Fouch et al., 2000); given that surface-wave models of the area (e.g., Darbyshire et al., 2007; Yuan and Romanowicz, 2010) indicate a consistently thick lithosphere, we will interpret our results largely in terms of lateral variations in lithospheric fabric.

Large-scale surface-wave models of North America indicate that mantle anisotropy in the mid-continent is multi-layered (Darbyshire and Lebedev, 2009; Yuan and Romanowicz, 2010), with a lithospheric fabric that changes across a mid-lithospheric discontinuity. Though our observations do not require multiple layers to explain the observed SKS/SKKS arrivals (see e.g. Fig. 7), we cannot rule this out, given the lack of depth resolution in teleseismic shear-wave splitting analysis. Our horizontal resolution, by contrast, is vastly superior to that of these surface-wave studies, so can make a much more detailed interpretation of lateral changes in fabric. Future studies combining SKS, surface-wave, and receiver-function observations will be required to completely constrain the three-dimensional pattern of anisotropy in central North America.

\subsection{Relationship to lithospheric velocity structure}

The Superior Province has been the subject of several tomographic studies (Sol et al., 2002; Frederiksen et al., 2007; Darbyshire and Lebedev, 2009; Frederiksen et al., 2013a), which detected significant lateral variations in lithospheric velocity. As teleseismic tomography, being based on near-vertical rays, has similar lateral resolution characteristics to SKS splitting, we will examine the relationship between our results and the most recently-published teleseismic P-velocity model (Frederiksen et al., 2013a). Fig. 13 shows the 
split-time contours from Fig. 11 overlain on two depth slices through the velocity model. Although there is no simple relationship between split time and seismic velocity, there are a number of interesting spatial relationships between the pattern of split times and the pattern of velocities.

The most evident relationship is that the strongest splits are associated with a large region of elevated velocities in the northwest of the map. This feature is termed the Western Superior Mantle Anomaly (WSMA) by Frederiksen et al. (2013a,b): a region of high lithospheric velocity in tomographic images and strong, consistent ENE-WSW fabric inferred from SKS measurements, bounded by sharp gradients in both velocity and split time. Our new measurements sharpen the eastern edge of the WSMA significantly, particularly near the Nipigon Embayment, and confirm that the transition between the WSMA and the more moderate fabric in the eastern Superior is sharp rather than gradational.

The Frederiksen et al. (2013a) model contains two low-velocity anomalies in the eastern Superior: a large feature interpreted to correspond to the northwestern limit of the Great Meteor hotspot track, and a smaller feature corresponding to the Nipigon Embayment (NE). Our new splitting measurements show that, while the Great Meteor feature corresponds to moderate split times typical of the eastern Superior, the NE feature corresponds fairly closely to a zone of very low split times. The low splits are displaced slightly eastward of the NE, which may be a consequence of the dominance of ray paths from the west and north (Fig. 3); for a source-receiver distance of $100^{\circ}$, the SKS pierce point at $250 \mathrm{~km}$ depth (around the base of the lithosphere) will be displaced $0.46^{\circ}$, or $51 \mathrm{~km}$, toward the source. The apparent shift of 
the low-splitting contour lines is larger than this; however, given that those contour lines are constrained by a small number of stations, it is possible that the apparent shift is largely a contouring artifact; denser measurements in and around the NE would be required in order to resolve this issue. With this caveat kept in mind, and given previous magnetotelluric observations of anomalous phase at lithospheric depth in the NE (Ferguson et al., 2005), we now have three lines of geophysical evidence indicating that the embayment is underlain by lithosphere significantly different from that of the surrounding Superior Province.

We also detected a similar zone of very low splits immediately east of Lake Superior. The velocity model does not contain a corresponding low velocity feature; note, however, that the ray coverage of this zone was quite poor (the region in question is greyed out due to lack of sampling in the $150 \mathrm{~km}$ depth slice, Fig. 13). A similar sampling issue is also at play along the axis of the MCR, given the lack of instrumentation within Lake Superior itself. The relationship between seismic velocity and fabric along the rift axis should become clearer once the SPREE data are incorporated into tomographic models.

\subsection{Mantle domains north of Lake Superior}

As noted in the previous section, our major new observation is the presence of two localized zones of minimal shear-wave splitting along the edge of the MCR, on the northern and eastern shores of Lake Superior (Fig. 11), one of which coincides with a known mantle velocity anomaly beneath the NE (Fig. 13). The near-zero split times in these two zones are similar to those previously detected beneath the Minnesota River Valley Terrane (Frederiksen 
et al., 2013b), though more localized, and are slightly lower than the values detected along the MCR axis, given our limited set of measurements within the MCR itself. The fact that the low-splitting zones are both adjacent to the MCR suggests some causal relationship.

The first question is whether these low-splitting zones actually represent an absence of coherent fabric, versus an interference effect of more complex layering (as suggested by Ferré et al., 2014, for a similar low-split region in southern Minnesota). We can address this by comparing the split time measurements in Fig. 11 to the transverse/radial (T/R) energy ratios in Fig. 4. We generated synthetic back azimuth-averaged $\mathrm{T} / \mathrm{R}$ ratios and split times for a two-layer model whose layers exhibit split times of 0.4 and $0.6 \mathrm{~s}$, respectively, with varying angles between the fast $\mathrm{S}$ polarization directions of the two layers. The results (Fig. 14a) indicate that the required degree of cancellation only occurs if the two layers' fast polarization directions deviate by less than $10^{\circ}$ from perfect $90^{\circ}$ opposition, while the $\mathrm{T} / \mathrm{R}$ ratio is more sensitive to misalignment. Thus, for moderately misaligned layers, we would expect the $\mathrm{T} / \mathrm{R}$ ratio to be low in proportion to the split time. In Fig. 14b, the $\mathrm{T} / \mathrm{R}$ ratio and the split time are shown to be closely correlated, with no obviously low $\mathrm{T} / \mathrm{R}$ values; we conclude that our observations do not require a contribution from multiple-layer interference. The stations at which we see very low splits also correspond to low $(<7 \%)$ energy ratios, indicating that the low-splitting zones are zones where very little energy is rotated out of the radial plane by any means, including 3-D velocity variations or spatiallyvarying anisotropy with a horizontal axis; anisotropy with a vertical axis of symmetry cannot be ruled out by SKS splitting data. 
The northern low-splitting zone is the easiest to interpret, given that it corresponds fairly closely to the Nipigon Embayment, as well as to a low-velocity anomaly and a magnetotelluric phase anomaly at lithospheric depths. The NE was a locus of extensive magmatism in the Proterozoic, roughly contemporaneous with the MCR (Hart and MacDonald, 2007). The predominance of sills over dykes suggests that the NE was not extensional at the time of emplacement, though north-trending extensional structures in the NE predate MCR magmatic activity by ca. 200 Ma. The lack of a gravity anomaly and the relatively small change in heat flow associated with the NE indicate that the overall volume of intrusives in the crust is small (Perry et al., 2004); however, the very low split times that we observe in the NE, the negative P-velocity anomaly (Frederiksen et al., 2007, 2013a), and the magnetotelluric anomaly at lithospheric depths (Ferguson et al., 2005) all indicate that the NE overlies a significantly modified lithosphere.

It is difficult to explain the loss of lithospheric fabric in the NE by purely deformational processes, particularly given the lack of evidence for extension. Given the evidence for mantle plume involvement in MCR magmatism (Nicholson and Shirey, 1990; Hutchinson et al., 1990; Hollings et al., 2012), we propose that the NE lithospheric anomaly represents thermal/chemical modification by a locus of plume impingement on the lithosphere, located somewhat off-axis from the associated rifting. This displacement of the rifting may indicate that the western Superior lithosphere was unusually resistant to deformation at the time (as previously suggested by Frederiksen et al., 2007, on other grounds).

The similar zone of weak splitting on the eastern shore of Lake Superior 
lacks an associated magmatic feature, though it is very similar in size and split time to that underlying the NE. The eastern weak-splitting zone does straddle the southern end of the KSZ (Fig. 10), suggesting a relationship; given the likely reactivation of KSZ structures by the MCR (Manson and Halls, 1997), we propose the possibility that MCR-related melt or fluids followed a KSZ-related zone of lithospheric weakness for ca. $150 \mathrm{~km}$, but failed to develop into an additional rift branch. The lack of a velocity anomaly beneath the low-splitting region may indicate that the infiltrating material was sufficient to reset the lithospheric fabric, but insufficient in volume to greatly affect the bulk composition, perhaps as a result of being more distal to the magma source than the NE.

The tomographic model of Frederiksen et al. (2013a) detected a linear low-velocity feature in the lithosphere beneath western Minnesota and the Dakotas, for which one suggested interpretation was a failed branch of the MCR. Unlike the features detected by this study, the linear low-velocity zone does not correspond to a zone of near-zero splitting (Frederiksen et al., 2013b). The Minnesota/Dakotas feature, the NE feature, and the KSZ feature all connect to the MCR at points at which the rift axis bends sharply (Fig. 13, lower panel), where a triple junction would be expected. Given the association between bends in the MCR and the features we have interpreted as failed branches, the possibility that additional cryptic failed branches exist at other sharp angles in the MCR axis would merit further investigation.

A major implication of our interpretation is that the Superior lithosphere controlled the trajectory of the MCR. We interpret three features (the KSZ, the $\mathrm{NE}$ and the failed branch) to represent failure of rifting to propagate 
into the Superior Province. If the Superior lithosphere was particularly resistant to being rifted, then the path of least resistance for the rift axis would run along the Superior margins, as in fact it does (Fig. 1). Frederiksen et al. (2007) previously argued that the lithosphere of the Western Superior is unusually strong, while the eastern Superior is weaker, based on the apparent deflection of the Great Meteor hotspot track by lithospheric deformation (Eaton and Frederiksen, 2007) and the lack of deflection of the Nipigon Embayment feature. If the entire Superior lithosphere was a barrier to rifting ca. $1.1 \mathrm{Ga}$, then the weakening of the eastern Superior must have occurred at a later date, and may have been related to the Great Meteor hotspot itself.

\section{Conclusions}

We have obtained shear-wave splits from teleseismic SKS and SKKS phases recorded at sixteen newly-deployed stations in the Superior Province north of Lake Superior, on the edge of the Mid-Continent Rift. This data set is supplemented by fifteen Earthscope Transportable Array stations south of the lake. Fast S polarization directions are consistently ENE-WSW to NE$\mathrm{SW}$, averaging $69^{\circ}$, while the split time varies strongly, ranging from 0.25 to $1.48 \mathrm{~s}$. Our data indicate that the lithosphere north of Lake Superior contains two highly localized domains of weak anisotropy, located adjacent to the Mid-Continent Rift axis as well as to the strongly anisotropic western Superior Province. One closely corresponds to a known mantle anomaly beneath the Nipigon Embayment, a magmatic feature whose relationship to the MCR is not completely understood. The other lies immediately east of Lake Superior and is aligned with the southern extremity of the Kapuskasing 
Structural Zoe. We interpret these zones to represent resetting of lithospheric fabric by MCR-related activity; along with an additional low-velocity feature previously detected beneath Minnesota and North and South Dakota, we interpret three offshoots of the MCR extending into the Superior lithosphere, all of which failed to generate crustal rifting. Our interpretation suggests that the lithosphere of the Superior Province was a barrier to rift propagation, and may have been indirectly responsible for the arcuate shape of the MCR.

\section{Acknowledgments}

Instrumentation for the Canadian portion of the SPREE project was provided by Earthscope and the IRIS PASSCAL program, and deployed by the kind permission of Ontario Parks and individual landowners. Algoma University and Lakehead University generously provided work space during deployment. Instrument deployers included Ghassan Aleqabi, Miguel Merino, Mulu Serzu, Allen Wywrot, and Taras Zaporozan. The SPREE field project was funded by NSF grant EAR-0952345; additional NSF grant PIs were Donna Jurdy and Doug Wiens. Additional field work and support for Oyekunle Ola were provided by NSERC grant RGPIN/261640-2008. Figures were prepared using Generic Map Tools (GMT); absolute plate motion was calculated using an online calculator provided by the University of Tokyo.

\section{References}

Amato, J.M., Boullion, A.O., Serna, A.M., Sanders, A.E., Farmer, G.L., Gherels, G.E., Wooden, J.L., 2008. Evolution of the Mazatzal province 
and the timing of the Mazatzal orogeny: Insights from $\mathrm{U}-\mathrm{Pb}$ geochronology and geochemistry of igneous and metasedimentary rocks in southern New Mexico. Geol. Soc. Am. Bull. 120, 328-346, doi:10.1130/B26200.1.

Auer, L., Boschi, L., Becker, T.W., 2014. Savani: A variable resolution wholemantle model of anisotropic shear velocity variations based on multiple data sets. J. Geophys. Res. 119, 3006-3034, doi:10.1002/(ISSN)2169-9356.

Barruol, G., Helffrich, G., Vauchez, A., 1997. Shear wave splitting around the northern Atlantic: frozen Pangaean lithospheric anisotropy? Tectonophysics 279, 135-148.

Bastow, I.D., Pilidou, S., Kendall, J.-M., Stuart, G.W., 2010. Meltinduced seismic anisotropy and magma assisted rifting in Ethiopia: Evidence from surface waves. Geochem. Geophys. Geosyst. 11, Q0AB05, doi:10.1029/2010GC003036.

Bickford, M.E., Wooden, J.L., Bauer, R.L., 2006. SHRIMP study of zircons from Early Archean rocks in the Minnesota River Valley: Implications for the tectonic history of the Superior Province. Geol. Soc Am. Bull. 118, 94-108. doi:10.1130/B25741.1

Calvert, A., Ludden, J., 1999. Archean continental assembly in the southeastern Superior Province of Canada. Tectonics 18, 412-429.

Cannon, W.F., Green, A.G., Hutchinson, D.R., Lee, M., Milkereit, B., Behrendt, J.C., Halls, H.C., Green, J.C., Dickas, A.B., Morey, G.B., Sutcliffe, R., Spencer, C., 1989. The North American Midcontinent Rift be- 
neath Lake Superior from Glimpce seismic reflection profiling. Tectonics 8, 305-332, doi:10.1029/TC008i002p00305.

Card, K., 1990. A Review of the Superior Province of the Canadian Shield, a Product of Archean Accretion. Precambrian Research 48, 9-156.

Darbyshire, F.A., Lebedev, S., 2009. Rayleigh wave phase-velocity heterogeneity and multilayered azimuthal anisotropy of the Superior Craton, Ontario. Geophys. J. Int. 176, 215-234, doi:10.1111/j.1365246X.2008.03982.x.

Darbyshire, F.A., Eaton, D.W., Frederiksen, A., Ertolahti, L., 2007. New insights into the lithosphere beneath the Superior Province from Rayleigh wave dispersion and receiver function analysis. Geophys. J. Int. 169, 10431068, doi:10.1111/j.1365-246X.2006.03259.x.

Davidson, A., 1998. An overview of Grenville Province geology, Canadian Shield, in: Geology of the Precambrian Superior and Grenville Provinces and Precambrian Fossils in North America, Geology of North America, vol. C-1, edited by S. B. Lucas and M. R. St-Onge, pp. 205-270, Geological Survey of Canada, Ottawa.

Eaton, D.W., Frederiksen, A., 2007. Seismic evidence for convectiondriven motion of the North American plate. Nature 446, 428-431, doi:10.1038/nature05675.

Eaton, D.W., Frederiksen, A., Miong, S.K., 2004. Shear-wave splitting observations in the lower Great Lakes region: Evidence for regional anisotropic 
domains and keel-modified asthenospheric flow. Geophys. Res. Lett. 31, L07610, doi:10.1029/2004GL019438.

Ferguson, I., Craven, J., Kurtz, R., Boerner, D., Bailey, R., Wu, X., Orellana, M., Spratt, J.E., Wennberg, G., Norton, A., 2005. Geoelectric response of Archean lithosphere in the western Superior Province, central Canada. Phys. Earth Planet. Int. 150, 123-143, doi:10.1016/j.pepi.2004.08.025.

Ferré, E.C., Gébelin, A., Conder, J.A., Christensen, N., Wood, J.D., Teyssier, C., 2014. Seismic anisotropy of the Archean crust in the Minnesota River Valley, Superior Province. Geophys. Res. Lett. 41, 1514-1522, doi:10.1002/2014GL060504.

Fouch, M., Fischer, K., Parmentier, E., Wysession, M., Clarke, T., 2000. Shear wave splitting, continental keels, and patterns of mantle flow. J. Geophys. Res 105, 6255-6275.

Frederiksen, A.W., I.J. Ferguson, D. Eaton, S.-K. Miong and Gowan, E., 2006. Mantle Fabric at Multiple Scales Across an Archean-Proterozoic Boundary, Eastern Ontario, Canada. Phys. Earth Plan. Int. 158, 240-263.

Frederiksen, A., Miong, S.K., Darbyshire, F.A., Eaton, D.W., Rondenay, S., Sol, S., 2007. Lithospheric variations across the Superior Province, Ontario, Canada: Evidence from tomography and shear wave splitting. J. Geophys. Res. 112, B07318, doi:10.1029/2006JB004861,2007.

Frederiksen, A., Bollmann, T., Darbyshire, F., Lee, S., 2013a. Modification of Continental lithosphere by tectonic processes: a tomographic image of central North America. J. Geophys. Res. 18, 1-16, doi:10.1002/jgrb.50060. 
Frederiksen, A., Deniset, I., Ola, O., Toni, D., 2013b. Lithospheric fabric variations in central North America: Influence of rifting and Archean tectonic styles. Geophys. Res. Lett. 40, 1-5, doi:10.1002/grl.50879.

Garnero, E.J., Maupin, V., Lay, T., Fouch, M.J., 2004. Variable azimuthal anisotropy in Earth's lowermost mantle. Science 306, 259-261.

Garnero, E.J., McNamara, A.K., 2008. Structure and Dynamics of Earth's Lower Mantle. Science 320, 626-628, doi:10.1126/science.1148028.

Gripp, A.E., Gordon, R.G., 1990. Current plate velocities relative to the hotspots incorporating the NUVEL-1 global plate motion model. Geophys. Res. Lett. 17, 1109-1112.

Gueydan, F., Morency, C., Brun, J.-P., 2008. Continental rifting as a function of lithosphere mantle strength. Tectonophysics 460, 83-93, doi:10.1016/j.tecto.2008.08.012.

Hart, T.R., MacDonald, C.A., 2007. Proterozoic and Archean geology of the Nipigon Embayment: implications for emplacement of the Mesoproterozoic Nipigon diabase sills and mafic to ultramafic intrusions. Can. J. Earth Sci. 44, 1021-1040, doi:10.1139/EO7-026.

He, X., Long, M.D., 2011. Lowermost mantle anisotropy beneath the northwestern Pacific: Evidence from PcS, ScS, SKS, and SKKS phases. Geochem. Geophys. Geosyst., 12, Q12012, doi:10.1029/2011GC003779.

Hollings, P., Hart, T., Richardson, A., MacDonald, C.A., 2007. Geochemistry of the Mesoproterozoic intrusive rocks of the Nipigon Embayment, 
northwestern Ontario: evaluating the earliest phases of rift development. Can. J. Earth. Sci. 44, 1087-1110, doi:10.1139/E06-127.

Hollings, P., Smyk, M., Cousens, B., 2012. The radiogenic isotope characteristics of dikes and sills associated with the Mesoproterozoic Midcontinent Rift near Thunder Bay, Ontario, Canada. Precambrian Research 214-215, 269-279, doi:10.1016/j.precamres.2011.11.006.

Hollings, P., Smyk, M., Heaman, L.M., Halls, H., 2010. The geochemistry, geochronology and paleomagnetism of dikes and sills associated with the Mesoproterozoic Midcontinent Rift near Thunder Bay, Ontario, Canada. Precambrian Research 183, 553-571, doi:10.1016/j.precamres.2010.01.012.

Huismans, R., Beaumont, C., 2011. Depth-dependent extension, two-stage breakup and cratonic underplating at rifted margins. Nature 473, 74-78, doi:10.1038/nature09988.

Hutchinson, D.R., White, R.S., Cannon, W.F., Schulz, K.J., 1990. Keweenaw hot spot: Geophysical evidence for a 1.1 Ga mantle plume beneath the Midcontinent Rift System. J. Geophys. Res. 95, 10869-10884, doi:10.1029/JB095iB07p10869.

Kay, I., Sol, S., Kendall, J., Thomson, C., White, D.J., Asudeh, I., Roberts, B., Francis, D., 1999. Shear wave splitting observations in the Archean craton of Western Superior. Geophys. Res. Lett. 26, 2669-2672.

Kong, F., Gao, S.S., Liu, K.H., 2015. Applicability of the Multiple-Event Stacking Technique for Shear-Wave Splitting Analysis. Bull. Seis. Soc. Am. 105, 3156-3166, doi:10.1785/0120150078. 
Long, M.D., 2009. Complex anisotropy in $\mathrm{D}^{\prime \prime}$ beneath the eastern Pacific from SKSSKKS splitting discrepancies. Earth Plan. Sci. Lett. 283, 181189, doi:10.1016/j.epsl.2009.04.019.

Manson, M.L., Halls, H.C., 1997. Proterozoic reactivation of the southern Superior Province and its role in the evolution of the Midcontinent rift. Can. J. Earth Sci., 34, 562-575, doi:10.1139/e17-045.

Mariano, J., Hinze, W., 1994. Structural interpretation of the Midcontinent Rift in eastern Lake Superior from seismic reflection and potential-field studies. Can. J. Earth Sci. 31, 619-628.

Merino, M., Keller, G.R., Stein, S., Stein, C., 2013. Variations in MidContinent Rift magma volumes consistent with microplate evolution. Geophys. Res. Lett. 40, 1513-516, doi:10.1002/grl.50295.

Musacchio, G., White, D.J., Asudeh, I., Thomson, C., 2004. Lithospheric structure and composition of the Archean western Superior Province from seismic refraction/wide-angle reflection and gravity modeling. J. Geophys. Res 109, B03304, doi:10.1029/2003JB002427.

Nicolas, A., Christensen, N.I., 1987. Formation of anisotropy in upper mantle peridotites-a review. In Composition, Structure and Dynamics of the Lithosphere-Asthenosphere System, K. Fuchs and C. Froidevaux, eds., American Geophysical Union, Washington, D.C., USA, doi:10.1029/GD016p0111.

Nicholson, S.W., Shirey, S.B., 1990. Midcontinent rift volcanism in the Lake 
Superior Region: $\mathrm{Sr}, \mathrm{Nd}$, and $\mathrm{Pb}$ isotopic evidence for a mantle plume origin. J. Geophys. Res. 95, 10851-10868, doi:10.1029/JB095iB07p10851.

North American Magnetic Anomaly Group, 2002. Digital data grids for the magnetic anomaly map of North America. U.S. Geological Survey Open File Report 02-414, U.S. Department of the Interior, Washington, D.C., USA.

Nowacki, A., Wookey, J., Kendall, J.-M., 2010. Deformation of the lowermost mantle from seismic anisotropy. Nature 467, 1091-1094, doi:10.1038/nature09507.

Ojakangas, R., Morey, G., Green, J., 2001. The Mesoproterozoic Midcontinent Rift System, Lake Superior Region, USA. Sediment. Geol., 141, 421-442.

Panning, M., Romanowicz, B., 2006. A three-dimensional radially anisotropic model of shear velocity in the whole mantle. Geophys. J. Int. 167, 361-379, doi:10.1111/j.1365-246X.2006.03100.x.

Percival, J., West, G., 1994. The Kapuskasing Uplift - a Geological and Geophysical Synthesis. Can. J. Earth Sci., 31, 1256-1286.

Percival, J.A., Sanborn-Barrie, M., Skulski, T., Stott, G.M., Helmstaedt, H., White, D.J., 2006. Tectonic evolution of the western Superior Province from NATMAP and Lithoprobe studies. Can. J. Earth. Sci. 43, 1085-1117, doi:10.1139/e06-062.

Perry, H., Jaupart, C., Mareschal, J.C., 2004. Heat flow in the Nipigon arm of 
the Keweenawan rift, northwestern Ontario, Canada. Geophys. Res. Lett. 31, L15607, doi:10.1029/2004GL020159.

Rondenay, S., Bostock, M.G., Hearn, T., White, D.J., Wu, H., Senechal, G., Ji, S., Mareschal, M., 2000. Teleseismic studies of the lithosphere below the Abitibi-Grenville Lithoprobe transect. Can. J. Earth Sci. 37, 415-426.

Shen, W., Ritzwoller, M.H., Schulte-Pelkum, V., 2013. Crustal and uppermost mantle structure in the central U.S. encompassing the Midcontinent Rift. Journal of Geophysical Research 118, doi:10.1002/jgrb.50321.

Samson, C., West, G., 1994. Detailed basin structure and tectonic evolution of the Midcontinent Rift System in eastern Lake Superior from reprocessing of GLIMPCE deep reflection seismic data. Can. J. Earth Sci. 31, 629-639.

Sexton, J., Henson, H., Jr, 1994. Interpretation of seismic reflection and gravity profile data in western Lake Superior. Can. J. Earth Sci. 31, 652660.

Silver, P. G., 1996. Seismic anisotropy beneath the continents: Probing the depths of geology, Annu. Rev. Earth Planet. Sci., 24, 385-432.

Silver, P. G., Chan, W.W., 1991. Shear-wave splitting and subcontinental mantle deformation, J. Geophys. Res., 96, 16,429-16,454.

Silver, P., Kaneshima, S., 1993. Constraints on Mantle Anisotropy Beneath Precambrian North America From a Transportable Teleseismic Experiment. Geophys. Res. Lett. 20, 1127-1130. 
Sol, S., Thomson, C., Kendall, J., White, D.J., VanDecar, J., Asudeh, I., 2002. Seismic tomographic images of the cratonic upper mantle beneath the Western Superior Province of the Canadian Shield - a remnant Archean slab? Phys. Earth. Planet. Int. 134, 53-69.

Stott, G.M., 2011. A revised terrane subdivision of the Superior Province in Ontario. Ontario Geological Survey, Miscellaneous Release-Data 278, ISBN 978-1-4435-6399-4.

Stein, S., van der Lee, S., Jurdy, D., Stein, C., Wiens, D., Wysession, M., Revenaugh, J., Frederiksen, A., Darbyshire, F., Bollmann, T., Lodewyk, J., Wolin, E., Merino, M., Tekverk, K., 2011. Learning from failure: The SPREE Mid-Continent Rift Experiment. GSA Today 21, 5-7. doi:10.1130/G120A.1.

Stein, C.A., Stein, S., Merino, M., Keller, G.R., 2014. Was the Mid-Continent Rift part of a successful seafloor-spreading episode? Geophys. Res. Lett. 41, doi:10.1002/2013GL059176.

Stein, C.A., Kley, J., Stein, S., Hindle, D., Keller, G.R., 2015. North America's Midcontinent Rift: When rift met LIP. Geosphere 11, 1607-1616, doi:10.1130/GES01183.1.

Tanner, J.G. and Members of the Committee for the Gravity Anomaly Map of North America, 1988. Gravity anomaly map of North America. The Leading Edge 7, 15-18.

Tommasi, A., Vauchez, A., 2001. Continental rifting parallel to ancient collisional belts: an effect of the mechanical anisotropy of the litho- 
spheric mantle. Earth Planet. Sci. Lett. 185, 199-210, doi:10.1016/S0012821X(00)00350-2.

Van Schmus, W., Hinze, W., 1985. The midcontinent rift system. Ann. Rev. Earth Planet. Sci. 13, 345-383.

Vauchez, A., Tommasi, A., Barruol, G., Maumus, J., 2000. Upper mantle deformation and seismic anisotropy in continental rifts. Physics and Chemistry of the Earth, Part A: Solid Earth and Geodesy 25, 111-117.

White, D.J., Musacchio, G., Helmstaedt, H.H., Harrap, R.M., Thurston, P.C., van der Velden, A., Hall, K., 2003. Images of a lower-crustal oceanic slab: Direct evidence for tectonic accretion in the Archean western Superior province. Geol. 31, 997-1000, doi:10.1130/G20014.1.

White, R., 1997. Mantle temperature and lithospheric thinning beneath the Midcontinent rift system: Evidence from magmatism and subsidence. Can. J. Earth Sci. 34, 464-475.

Whitmeyer, S.J. and Karlstrom, K.E., 2007. Tectonic model for the Proterozoic growth of North America. Geosphere 3, 220-259, doi: 10.1130/GES00055.1.

Wolfe, C.J., Silver, P.G., 1998. Seismic anisotropy of oceanic upper mantle: Shear wave splitting methodologies and observations. J. Geophys. Res 103, 749-771.

Wolin, E., Van der Lee, S., Bollmann, T.A., Wysession, M.E., Stein, S., Wiens, D.A., Darbyshire, F.A., Frederiksen, A.W., Revenaugh, J., 2015. 
843 Seasonal and diurnal variations in long-period noise at SPREE stations: 844 the influence of soil characteristics on shallow stations' performance. Sub845 mitted to Bull. Seis. Soc. Am.

846 Yang, B.B., Gao, S.S., Liu, K.H., Elsheikh, A.A., Lemnifi, A.A., Refayee, 847 H.A., Yu, Y., 2014. Seismic anisotropy and mantle flow beneath the north848 ern Great Plains of North America. J Geophys. Res. 119, 1971-1985, 849 doi:10.1002/2013JB010561.

850 Yuan, H., Romanowicz, B., 2010. Lithospheric layering in the North Ameri851 can craton. Nature 466, 1063-1068, doi:10.1038/nature09332. 


\section{Figures and Captions}

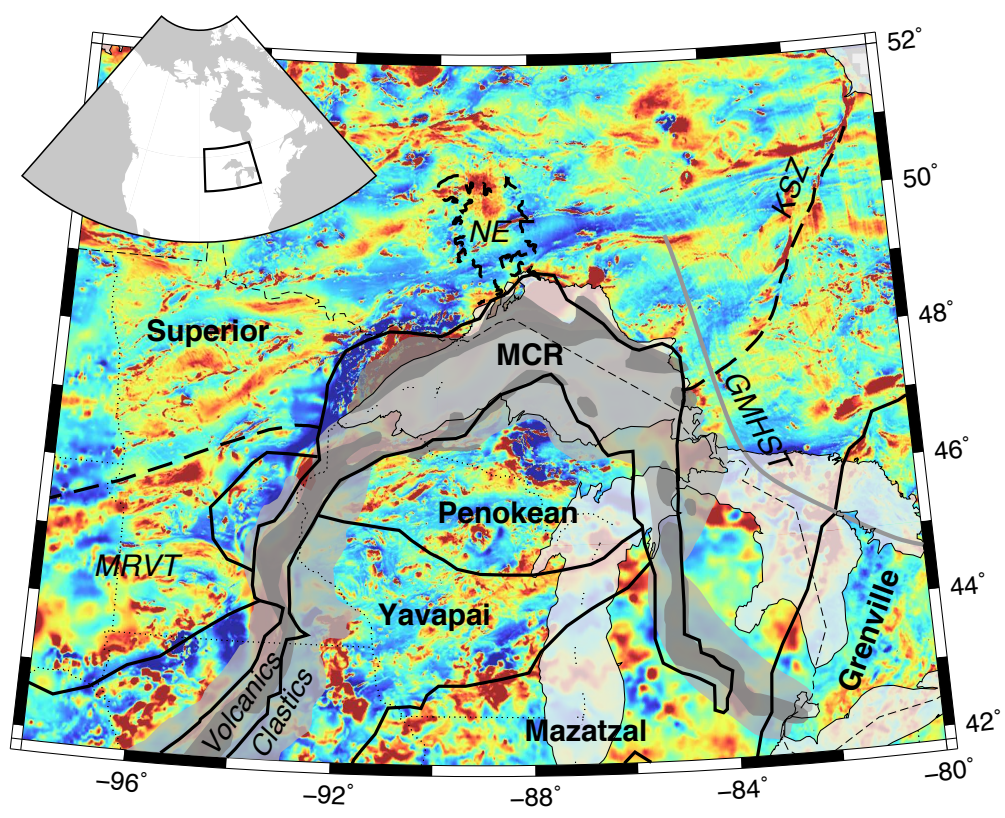

Figure 1: Geologic setting of this study, overlain on a map of magnetic anomalies (North American Magnetic Anomaly Group, 2002). MCR: Mid-Continent Rift, MRVT: Minnesota River Valley Terrane, NE: Nipigon Embayment, KSZ: Kapuskasing Structural Zone, GMHST: Great Meteor Hotspot Track. Solid black lines are tectonic province boundaries from Whitmeyer and Karlstrom (2007); dashed lines are boundaries of interest within the Superior Province (MRVT boundary from Bickford et al. (2006); NE boundary from the National Atlas of Canada, http://atlas.gc.ca/site/english/maps/geology.html). Hotspot track is from Eaton and Frederiksen (2007). Shaded regions are clastic (lighter) and volcanic (darker) rocks associated with the MCR, from Ojakangas et al. (2001). Inset shows location of study within North America (box). 


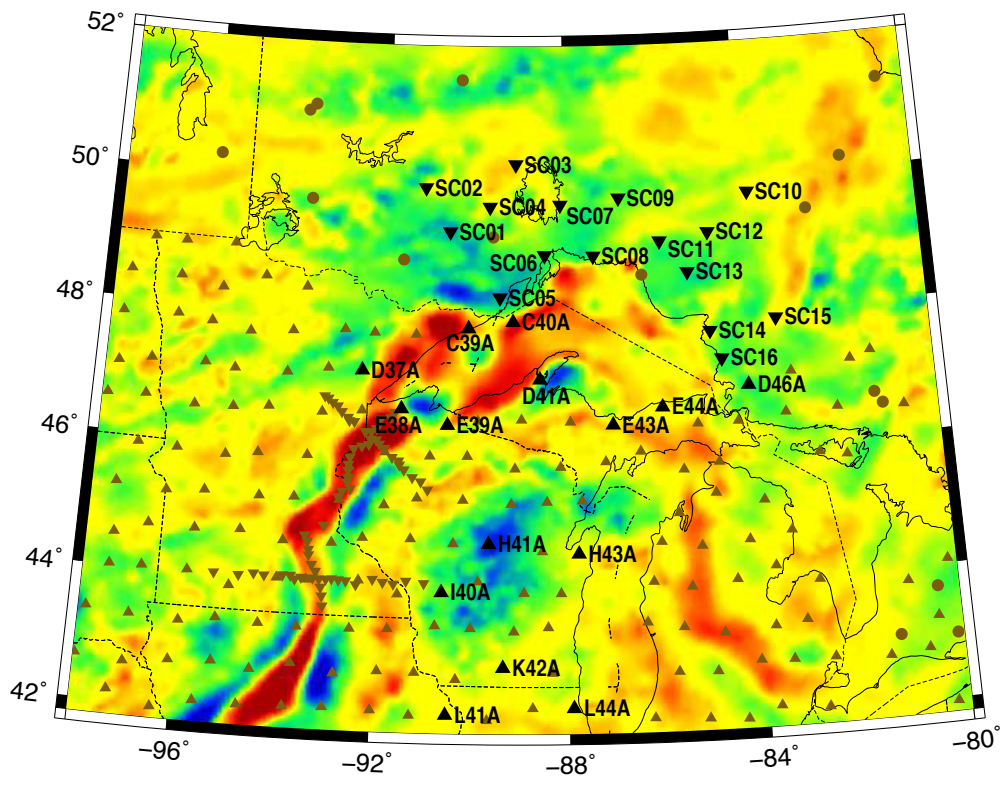

Figure 2: Seismic instrumentation in the study area, overlain on Bouguer gravity (Tanner et al., 1988). Black symbols show sites used in this study. Inverted triangles: Superior Province Rifting Earthscope Experiment (SPREE) instruments; upright triangles: Earthscope Transportable Array instruments; circles: Canadian National Seismograph Network instruments. 

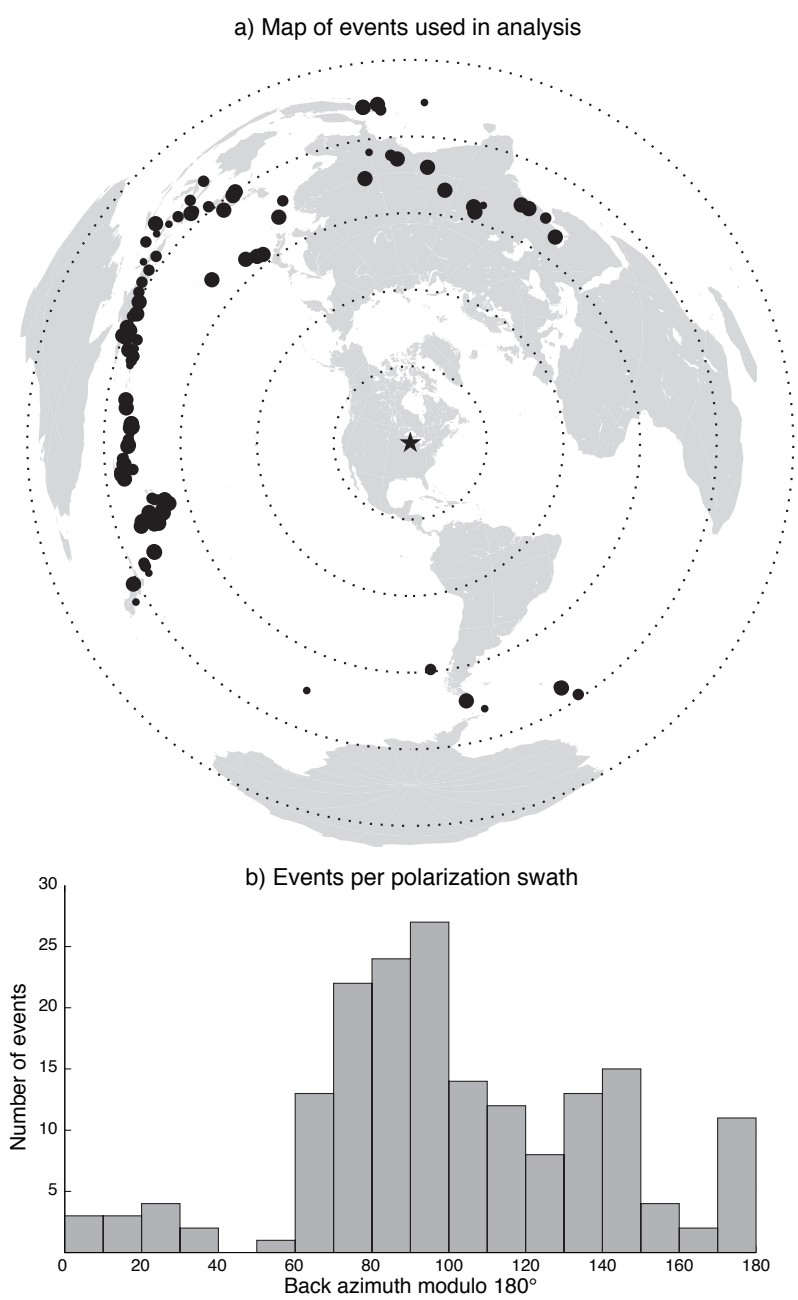

Figure 3: a) Locations of events used in the shear-wave splitting analysis and judged to be of quality 3 (out of 5 ) or greater. Larger circles represent higher-quality events; the star indicates the approximate centre of the study area. b) Histogram of the events in (a), binned by the associated polarization direction. 


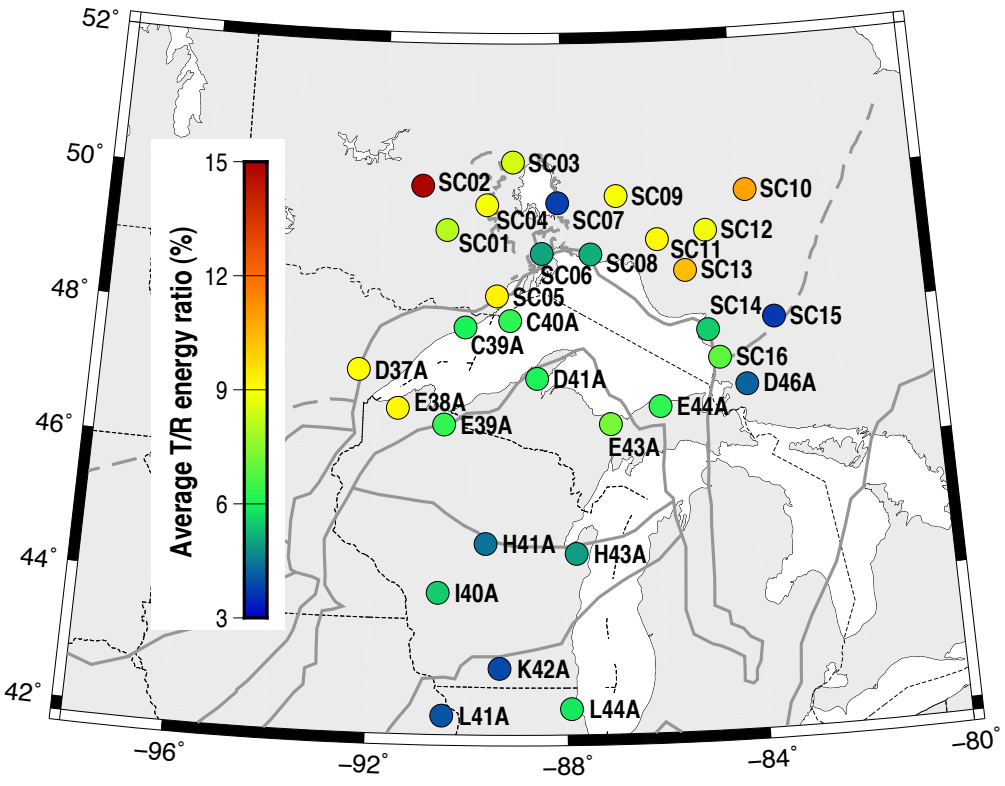

Figure 4: Average ratio of transverse to radial energy at each station, for all events of quality $\geq 3$. This ratio is a direct measure of the effect of anisotropy on the SKS and SKKS traces. 

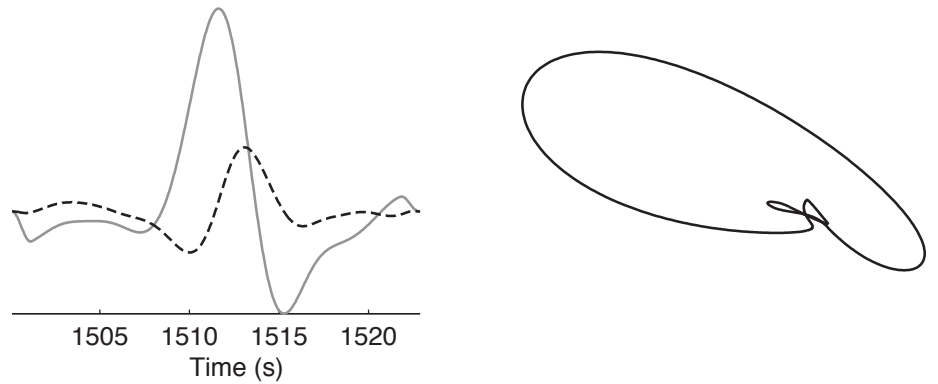

Second eigenvalue (darker: lower value)
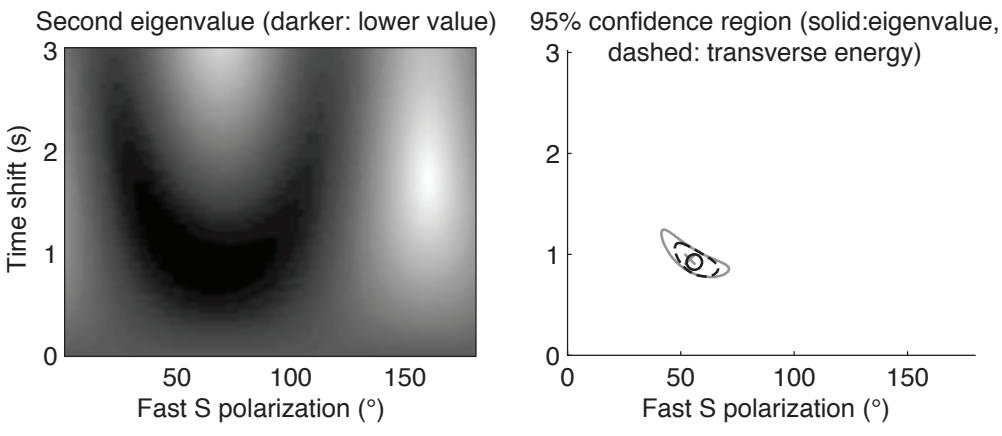

Recovered radial (solid) \& transverse (dashed)

Reconstructed particle motion
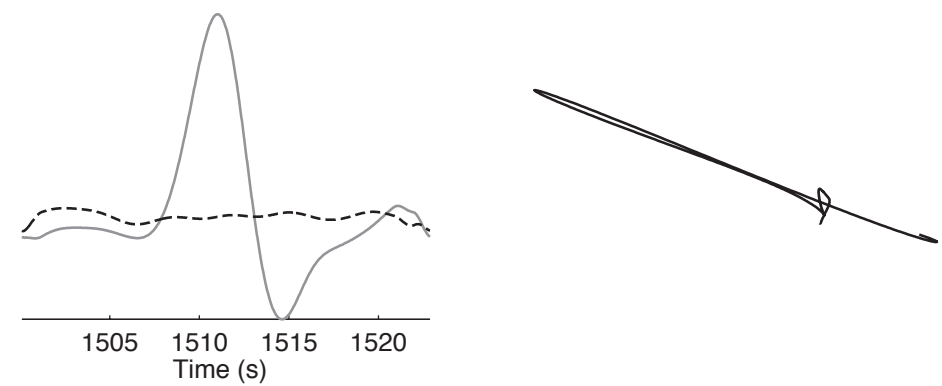

Figure 5: Splitting measurement for a sample high-quality SKS pulse (quality level 5) recorded at station SC05. The event occurred on 2011/12/14 at 05:04:59 in Papua New Guinea. Top two panels show unprocessed data (band-pass filtered between 0.02 and 0.2 $\mathrm{Hz}$ ): radial and transverse traces (left) and particle motion (right). Middle two panels show the grid search over split time and fast polarization direction: second-eigenvalue misfit surface (left, darker values are lower misfit) and best-fit values with $95 \%$ confidence contour from F-test (both eigenvalue and transverse-energy results are shown). Bottom two panels show the result of correcting the traces using the eigenvalue solution: recovered radial and transverse traces (left) and recovered particle motion (right). 


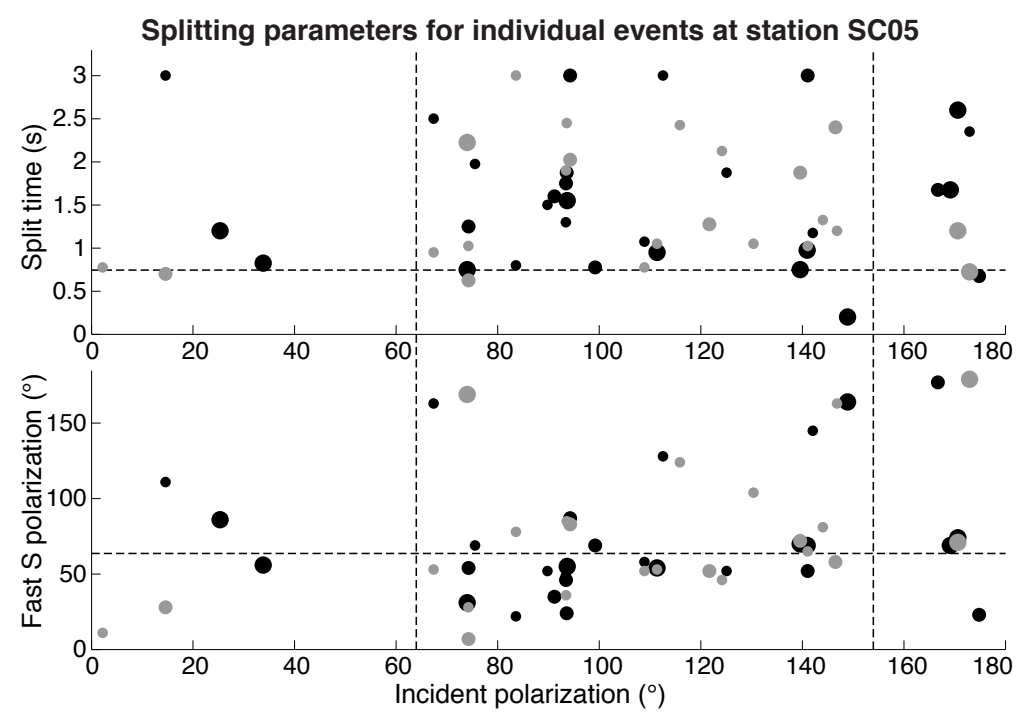

Figure 6: Recovered single-event splitting parameters for all events of quality $\geq 3$ recorded at station SC05, plotted against the incident polarization angle (the back-azimuth modulo $180^{\circ}$ ). Black circles are SKS measurements, grey circles are SKKS measurements; circle size indicates measurement quality (from 3 through 5). Horizontal dashed lines are the final fast S polarization direction and split time values obtained at SC05; vertical dashed lines indicate the expected null directions given the obtained fast polarization. 


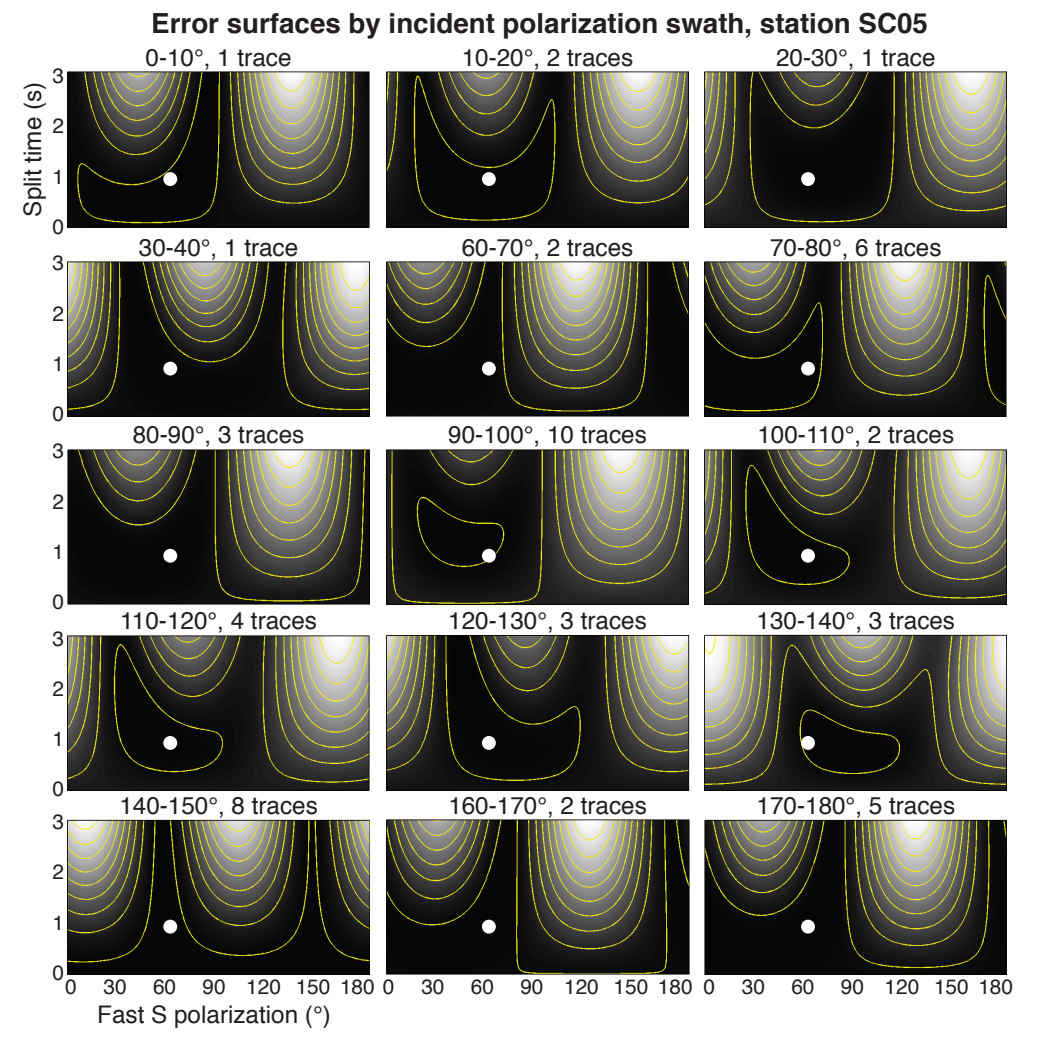

Figure 7: Eigenvalue misfit surfaces for all events of quality $\geq 3$ recorded at station SC05, stacked in $10^{\circ}$ incident-polarization swaths. The white circle is the composite solution for SC05. Note how it is consistent with all of the swath misfit surfaces. 

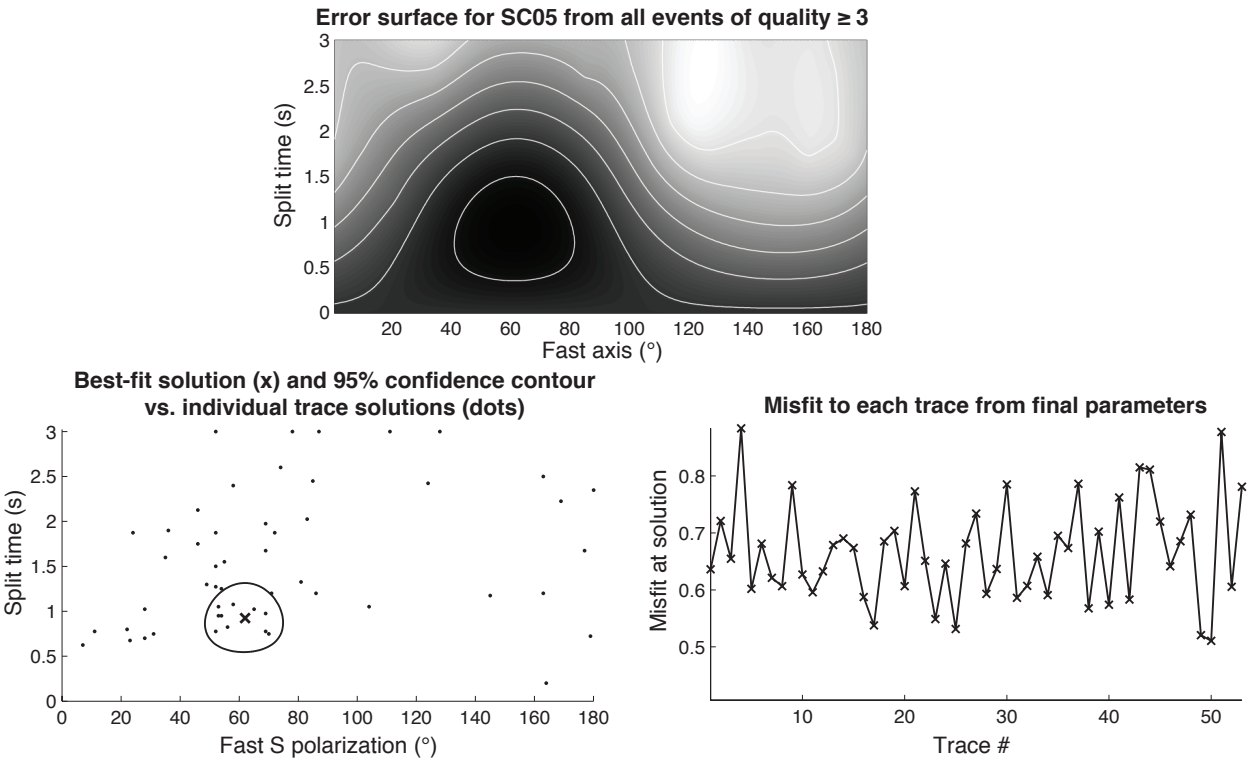

Figure 8: Top: final misfit-surface stack for events of quality $\geq 3$ at station SC05, formed by stacking all of the swath stacks in Fig. 7 with equal weight. Bottom left: bestfit solution and 95\% error contour, compared to the individual-event solutions (dots). Bottom right: scaled misfit of each individual trace to the best-fit solution. 


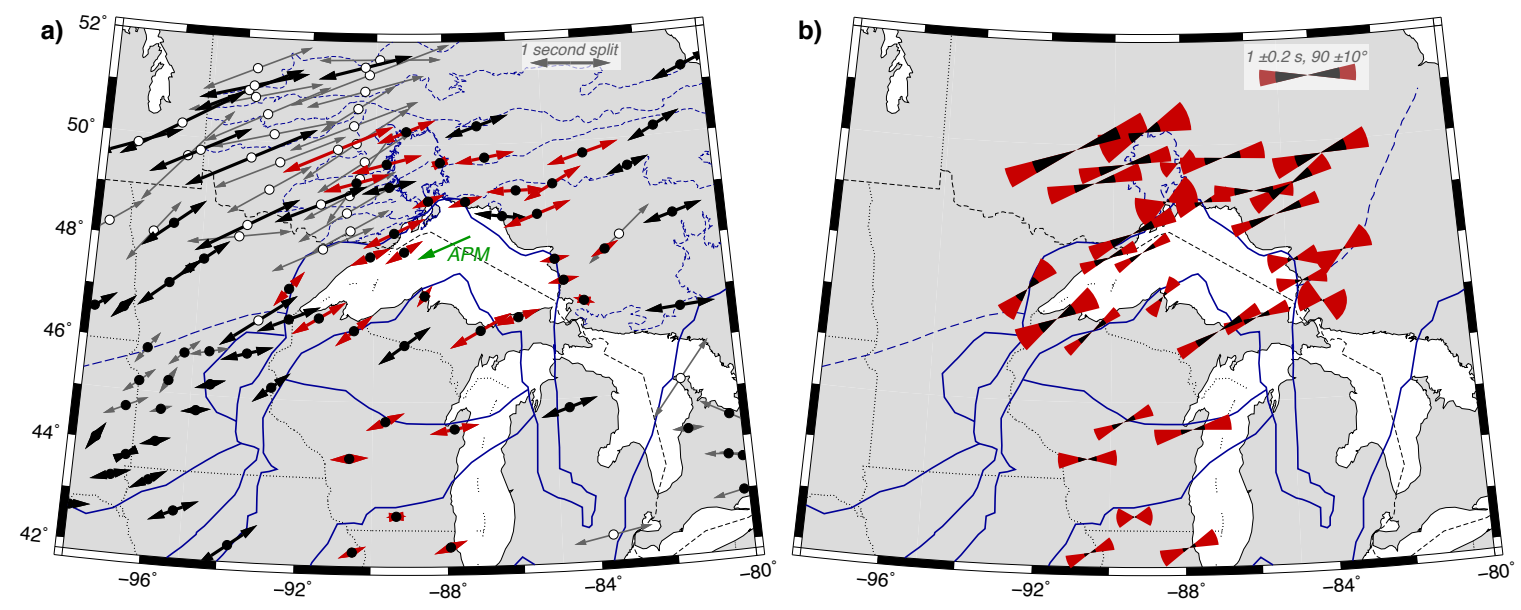

Figure 9: a) Map of splitting measurements in the study area. Arrow orientation is fast $\mathrm{S}$ polarization direction, and arrow length is proportional to split time. Red arrows are the results of this study; black arrows are previously published studies using the same methodology (Frederiksen et al., 2006, 2007, 2013b), and grey arrows are other published studies (Silver and Kaneshima, 1993; Barruol et al., 1997; Kay et al., 1999; Rondenay et al., 2000; Eaton et al., 2004; Ferré et al., 2014). White circles indicate split times $>1 \mathrm{~s}$. Blue lines are tectonic boundaries, as in Fig. 1, with the addition of Superior subprovince boundaries within Ontario (thin dashed lines; Stott, 2011). The green arrow indicates the direction of absolute plate motion, from model HS3-NUVEL-1A (Gripp and Gordon, 1990). b) Error bars on splitting measurements. The width of the wedge indicates the range of angles included in the error bar; the length of the black wedge represents the minimum possible split time, while the red wedge represents the maximum. 


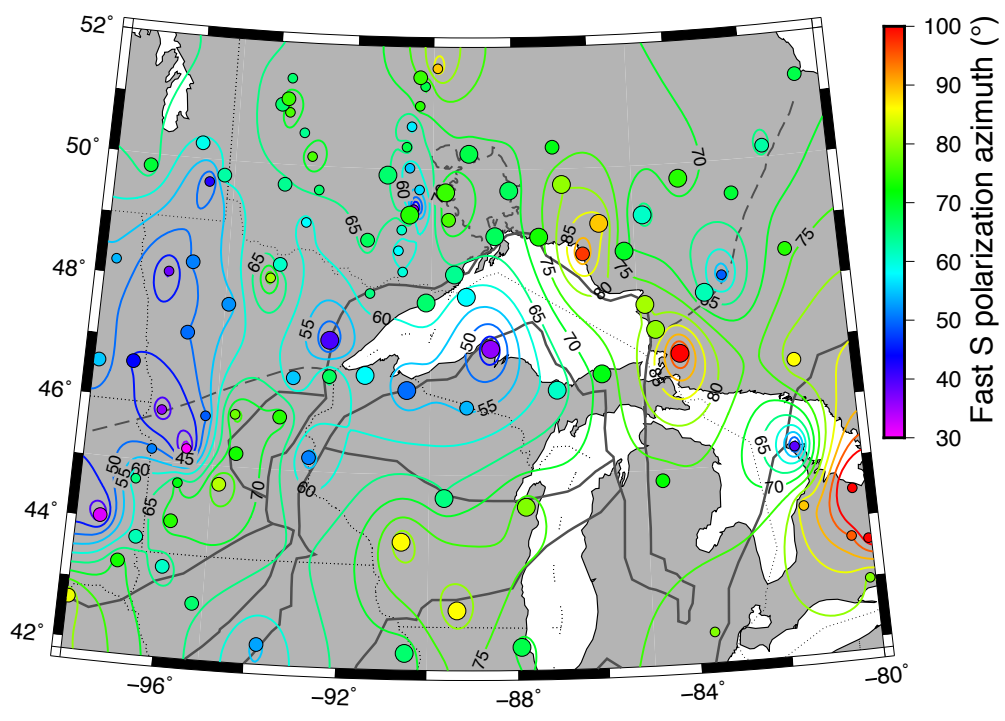

Figure 10: Contour map of fast S polarization directions (in degrees) across the study area. Large circles: this study; medium circles: published studies with the same methodology; small circles: other studies. Grey lines are tectonic boundaries (see Fig. 1). 


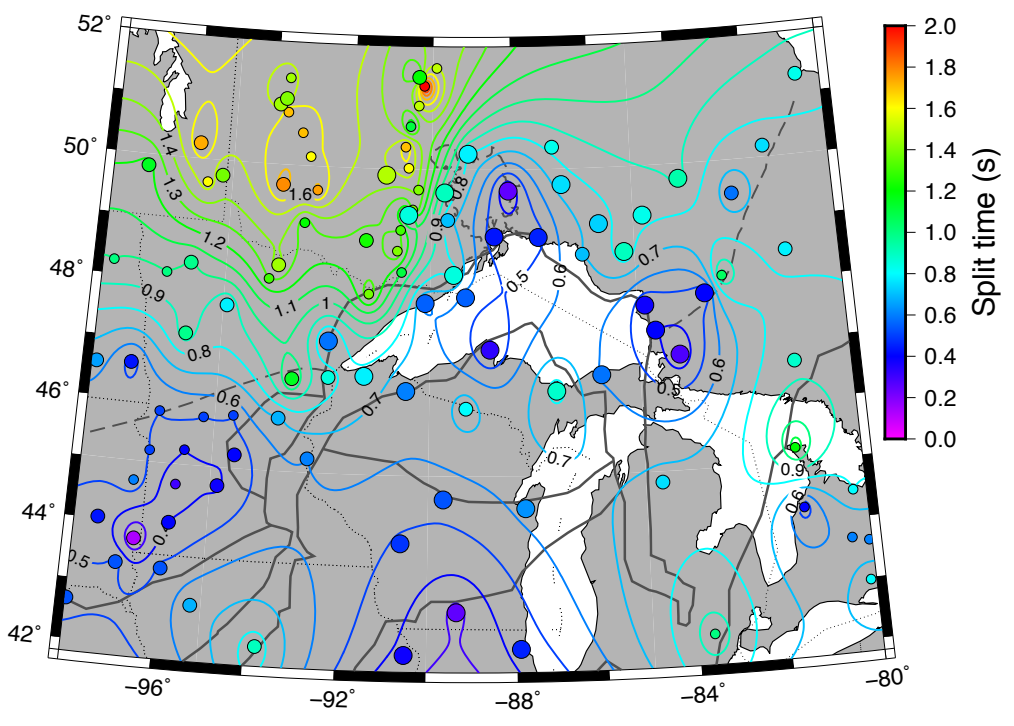

Figure 11: Contour map of split times (in seconds) across the study area. Large circles: this study; medium circles: published studies with the same methodology; small circles: other studies. Grey lines are tectonic boundaries (see Fig. 1). 


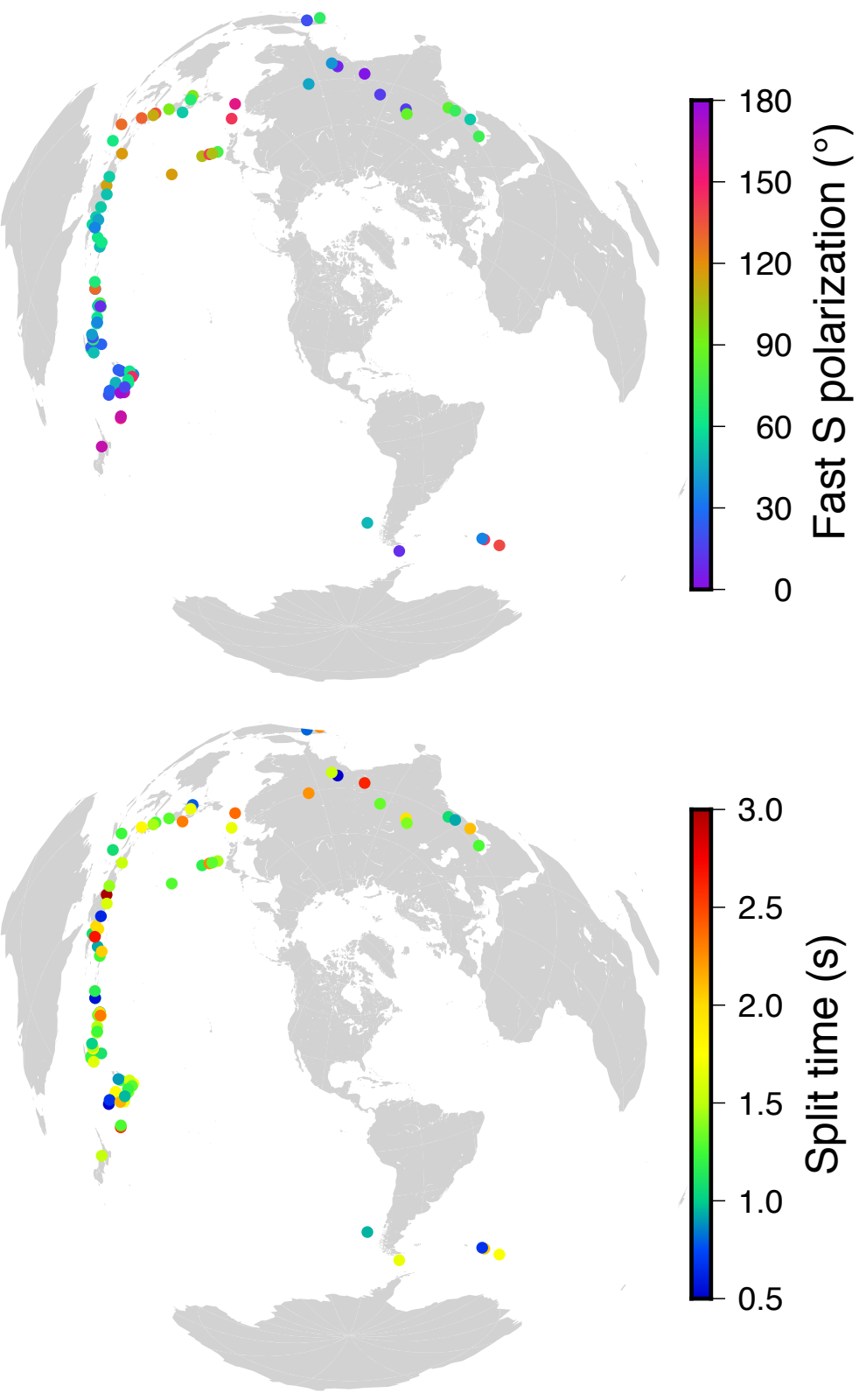

Figure 12: Fast polarization directions (top panel) and split times (bottom panel) for individual events, averaged over all stations. The fast polarization directions show coherent spatial variations indicating a deep-mantle influence. 

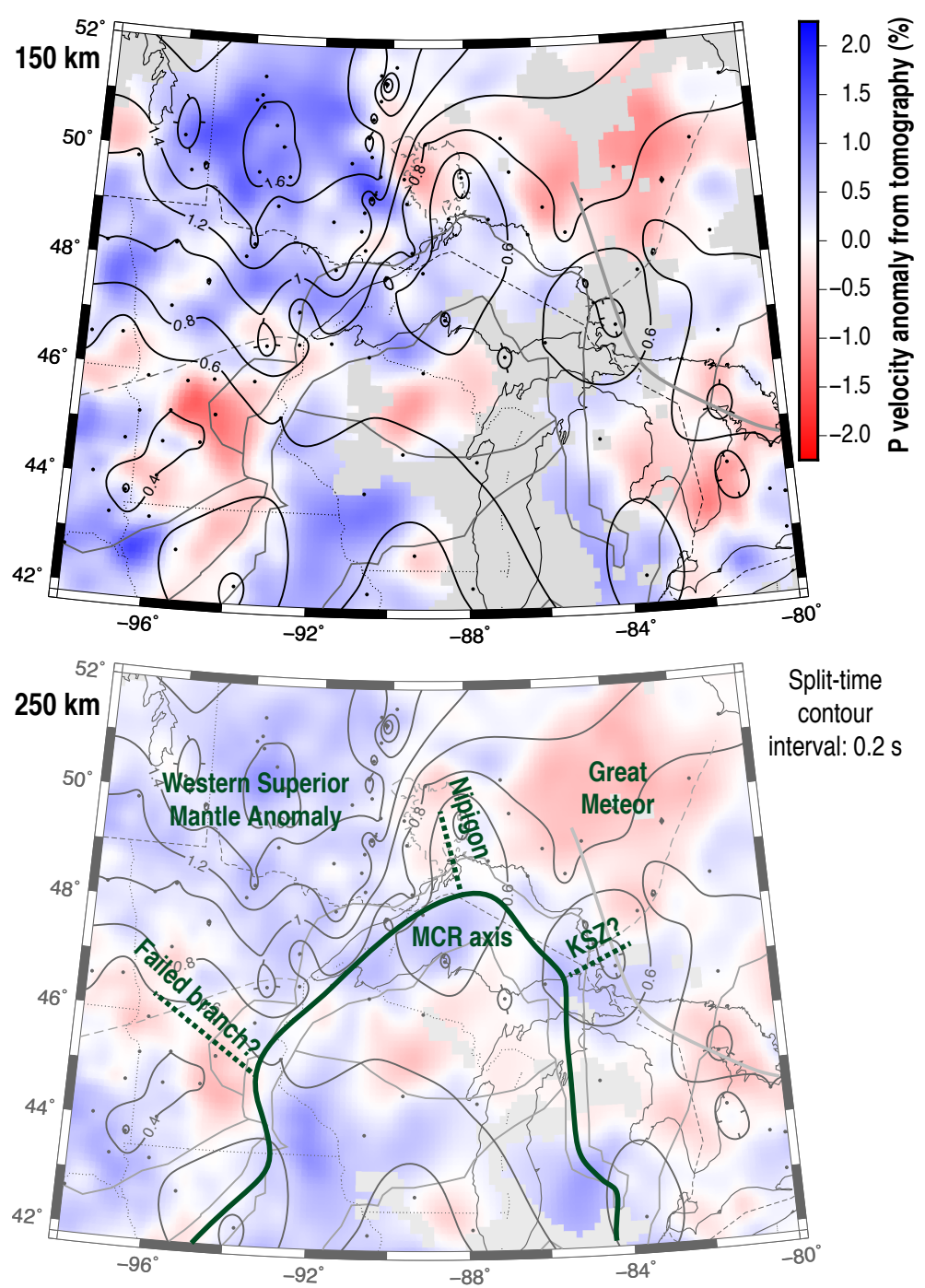

Figure 13: Contours of split time in seconds (black) overlain on tomographic $\mathrm{P}$ velocities at $150 \mathrm{~km}$ depth (top) and $250 \mathrm{~km}$ depth (bottom) from the teleseismic model of Frederiksen et al. (2013a); black dots are locations of stations used to obtain the contours. Light grey regions indicate that the tomographic model lacks ray coverage. Dark grey lines are tectonic boundaries (see Fig. 1). The $250 \mathrm{~km}$ slice is overlain with interpretation (see text for details). 

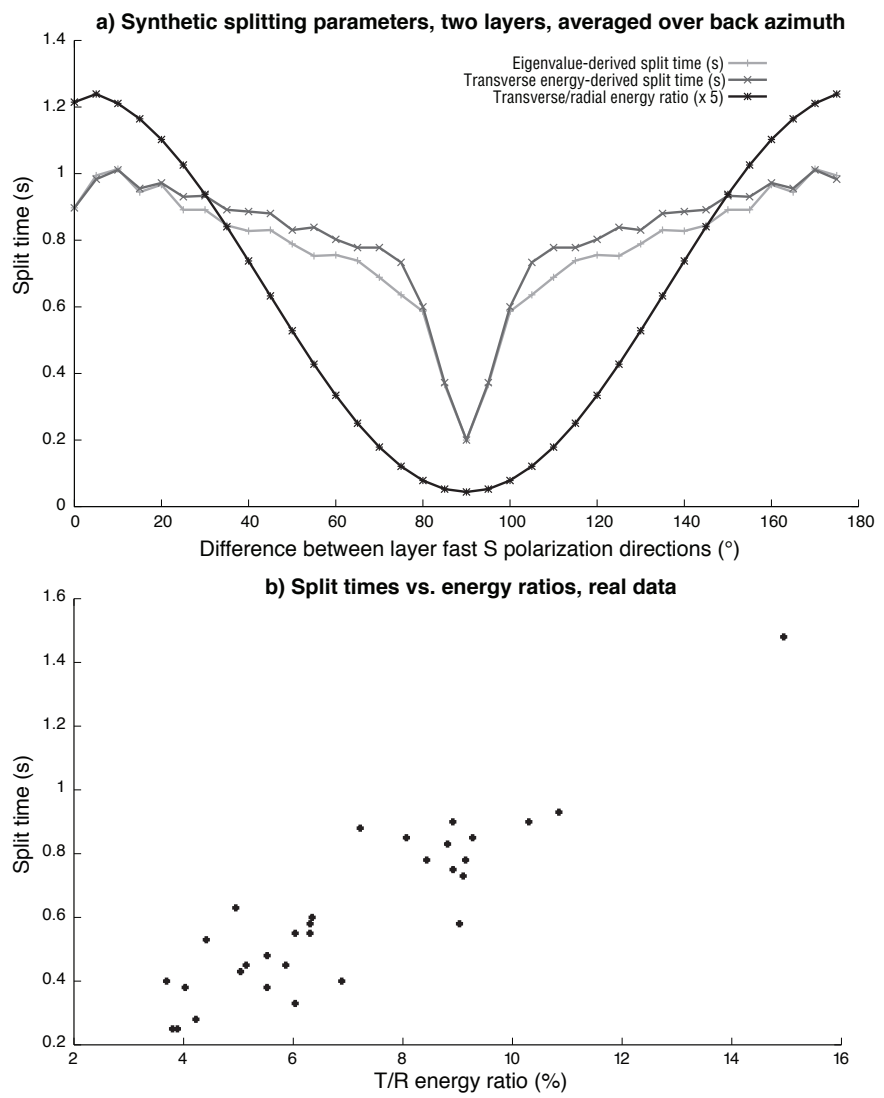

Figure 14: a) Synthetic directionally-averaged split times and transverse/radial $(\mathrm{T} / \mathrm{R})$ energy ratios for a two-layer model in which the upper layer has a split time of $0.4 \mathrm{~s}$ and the lower layer has a split time of $0.6 \mathrm{~s}$, for a range of angles between the two layers' fast polarization directions. b) Split times plotted against $\mathrm{T} / \mathrm{R}$ ratios for real data. 
Table 1: Final splitting measurements at all stations. Stations with codes starting with "SC" are SPREE stations, while the others are TA stations. $\phi$ is the fast S polarization direction and $\delta t$ is the split time. The last three columns indicate the number of SKS and SKKS traces contributing to the final result, and the quality threshold used.

\begin{tabular}{cccccccc} 
Station & Lat. & Lon. & $\phi\left(^{\circ}\right)$ & $\delta t(\mathrm{~s})$ & SKS & SKKS & Quality \\
\hline C39A & 47.817 & -90.129 & $66 \pm 12$ & $0.55 \pm 0.18$ & 13 & 17 & 4 \\
C40A & 47.915 & -89.151 & $58 \pm 10$ & $0.55 \pm 0.20$ & 16 & 8 & 4 \\
D37A & 47.160 & -92.430 & $40 \pm 19$ & $0.58 \pm 0.25$ & 31 & 21 & 4 \\
D41A & 47.061 & -88.566 & $36 \pm 19$ & $0.33 \pm 0.20$ & 14 & 11 & 4 \\
D46A & 46.890 & -84.040 & $107 \pm 41$ & $0.28 \pm 0.33$ & 9 & 5 & 3 \\
E38A & 46.606 & -91.554 & $58 \pm 16$ & $0.78 \pm 0.30$ & 23 & 10 & 4 \\
E39A & 46.378 & -90.556 & $50 \pm 10$ & $0.60 \pm 0.20$ & 21 & 10 & 4 \\
E43A & 46.376 & -86.995 & $61 \pm 8$ & $0.88 \pm 0.25$ & 21 & 15 & 4 \\
E44A & 46.620 & -85.921 & $71 \pm 11$ & $0.58 \pm 0.25$ & 20 & 13 & 3 \\
H41A & 44.616 & -89.653 & $65 \pm 12$ & $0.53 \pm 0.23$ & 18 & 10 & 4 \\
H43A & 44.470 & -87.770 & $79 \pm 12$ & $0.63 \pm 0.33$ & 19 & 11 & 3 \\
I40A & 43.892 & -90.618 & $86 \pm 16$ & $0.48 \pm 0.25$ & 20 & 10 & 4 \\
K42A & 42.779 & -89.346 & $86 \pm 33$ & $0.25 \pm 0.20$ & 15 & 10 & 3 \\
L41A & 42.075 & -90.498 & $66 \pm 16$ & $0.38 \pm 0.23$ & 21 & 8 & 4 \\
L44A & 42.178 & -87.912 & $68 \pm 17$ & $0.45 \pm 0.28$ & 18 & 11 & 3 \\
SC01 & 49.250 & -90.568 & $74 \pm 11$ & $0.85 \pm 0.33$ & 18 & 16 & 3 \\
SC02 & 49.895 & -91.141 & $66 \pm 8$ & $1.48 \pm 0.35$ & 22 & 8 & 4 \\
SC03 & 50.254 & -89.094 & $68 \pm 19$ & $0.78 \pm 0.38$ & 23 & 11 & 3 \\
SC04 & 49.624 & -89.675 & $75 \pm 10$ & $0.90 \pm 0.25$ & 16 & 13 & 4 \\
SC05 & 48.280 & -89.443 & $64 \pm 10$ & $0.85 \pm 0.28$ & 19 & 9 & 4 \\
SC06 & 48.905 & -88.446 & $67 \pm 31$ & $0.43 \pm 0.35$ & 8 & 7 & 3 \\
SC07 & 49.651 & -88.088 & $67 \pm 28$ & $0.25 \pm 0.20$ & 14 & 8 & 4 \\
SC08 & 48.888 & -87.357 & $73 \pm 17$ & $0.45 \pm 0.23$ & 15 & 12 & 3 \\
SC09 & 49.740 & -86.755 & $80 \pm 12$ & $0.75 \pm 0.30$ & 14 & 11 & 3 \\
SC10 & 49.753 & -83.817 & $74 \pm 13$ & $0.93 \pm 0.28$ & 12 & 13 & 3 \\
SC11 & 49.084 & -85.856 & $89 \pm 11$ & $0.73 \pm 0.25$ & 20 & 12 & 3 \\
SC12 & 49.189 & -84.763 & $61 \pm 12$ & $0.83 \pm 0.25$ & 18 & 9 & 4 \\
SC13 & 48.613 & -85.258 & $70 \pm 8$ & $0.90 \pm 0.23$ & 10 & 9 & 4 \\
SC15 & 47.723 & -84.814 & $81 \pm 23$ & $0.38 \pm 0.25$ & 16 & 13 & 4 \\
& 47.305 & -84.588 & $80 \pm 17$ & $0.40 \pm 0.23$ & 20 & 10 & 4
\end{tabular}

